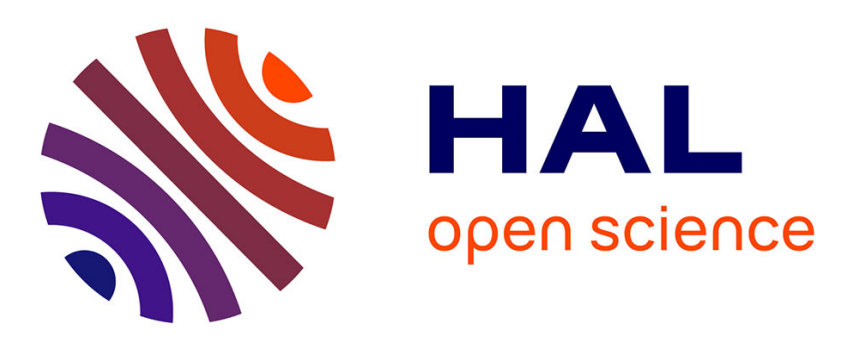

\title{
A wide range kinetic modeling study of PAH formation from liquid transportation fuels combustion
}

\author{
Mamady Keita, André Nicolle, Abderrahman El Bakali
}

\section{To cite this version:}

Mamady Keita, André Nicolle, Abderrahman El Bakali. A wide range kinetic modeling study of PAH formation from liquid transportation fuels combustion. Combustion and Flame, 2016, 174, pp.50 - 67. 10.1016/j.combustflame.2016.09.016 . hal-01487784

\section{HAL Id: hal-01487784 https://hal.science/hal-01487784}

Submitted on 13 Mar 2017

HAL is a multi-disciplinary open access archive for the deposit and dissemination of scientific research documents, whether they are published or not. The documents may come from teaching and research institutions in France or abroad, or from public or private research centers.
L'archive ouverte pluridisciplinaire HAL, est destinée au dépôt et à la diffusion de documents scientifiques de niveau recherche, publiés ou non, émanant des établissements d'enseignement et de recherche français ou étrangers, des laboratoires publics ou privés. 


\title{
A wide range kinetic modeling study of PAH formation from liquid transportation fuels combustion
}

\author{
Mamady Keita ${ }^{1,2, *}$, André Nicolle ${ }^{1}$, Abderrahman El Bakali² \\ ${ }^{1}$ IFP Energies nouvelles, 1 et 4 avenue de Bois-Préau, 92852 Rueil-Malmaison, France ; Institut Carnot IFPEN \\ Transports Energie, France \\ ${ }^{2}$ Laboratoire PC2A, UMR CNRS 8522, 59655 Villeneuve d'Ascq, France \\ * Corresponding author: keita.mamad@gmail.com
}

\begin{abstract}
A new detailed chemical kinetic mechanism was herein developed to describe accurately the combustion of liquid transportation fuels (gasoline, jet-A1 and diesel fuel) as well as laboratory fuels (single components) over an extended range of equivalence ratios, temperatures, pressures and dilution levels. This mechanism is able to simultaneously reproduce PAH mole fraction profiles, ignition delay times and flame speeds for a variety of fuels. Three surrogate mixtures of n-decane, iso-octane and npropylbenzene in different amounts were formulated to represent the above-mentioned commercial fuels based on their derived cetane numbers and threshold sooting indexes. Based on this mechanism, the impacts of fuel composition (ethylene vs. jet-A1 fuel) and reaction progress (height above the burner) on the respective importance of benzene and naphthalene formation pathways were characterized. In addition to HACA mechanism, naphthalene was found to be formed mainly from phenyl+vinylacetylene and benzyl+propargyl pathways for jet A-1 flames. A path involving dibenzofuran oxidation was also found to play a key role in naphthalene production in jet-A1 flame, highlighting the significant contribution of oxygenated compounds to PAH production.
\end{abstract}

Keywords: Liquid Transportation Fuels; Surrogate; Chemical kinetic mechanism; PAH; Modeling 


\section{Introduction}

Aromatic hydrocarbons are considered as major precursors of soot [1] and their impact on health [2,3] and environment [4] has been clearly established. It is therefore important to predict aromatics production accurately to design and control cleaner and sustainable transportation technologies. However, fuel composition and combustion conditions impact considerably aromatic production pathways. In fact, benzene formation from n-alkanes and acetylene combustion was shown to involve mostly propargyl radical recombination or reaction with allyl radical $[5,6]$, whereas additional $\mathrm{C}_{4}$ paths $\left(\mathrm{nC}_{4} \mathrm{H}_{3}+\mathrm{C}_{2} \mathrm{H}_{2}\right.$ and $\left.\mathrm{nC}_{4} \mathrm{H}_{5}+\mathrm{C}_{2} \mathrm{H}_{2}\right)$ may also come into play in the combustion of buta-1,3-diene [5], n-butane [7], ethylene [8-10] or iso-octane [10,11]. Several other benzene production pathways like cycloalkanes sequential dehydrogenation [5,12], toluene decomposition [10] or cyclopentadienyl combination with methyl radical [6] have also been evidenced. Although the production of naphthalene from benzene may proceed through the popular HACA mechanism [13-16] consisting in sequential $\mathrm{H}$ abstractions and acetylene additions, several alternate pathways have been put forward such as those involving methyl, vinyl, propargyl, vinylacetylene, cyclopentadienyl or phenyl addition and subsequent cyclization $[13,17-$ 19]. Besides, cyclopentadienyl radicals recombination [13], as well as benzyl radical reaction with propargyl [17] or acetylene [20] may be favored under specific conditions (doped methane flames, toluene pyrolysis). Slavinskaya et al. [9] included the phenyl+vinylacetylene pathway to improve the description of naphthalene production in rich ethylene flames. Recently, biomass combustion studies [21,22] suggested a possible contribution of dibenzofuran oxidation to naphthalene formation.

While most of the kinetic modeling studies of naphthalene production focused on single component fuels combustion, few works addressed the important issue of aromatics production during liquid transportation fuels combustion. To the best of our knowledge, no systematic comparative modeling study of the relative importance of naphthalene production pathways for laboratory fuels (e.g ethylene) and commercial liquid transportation fuels (e.g jet-A1 fuel) has not been published yet. As far as we know, examining the impact of fuel structural properties on 
aromatics production paths is meaningful and useful since ethylene is an important intermediate in transportation fuels combustion and may be present in recirculated exhaust gas [23], thereby impacting PAH production paths. Sarofim and coworkers [5] focused on comparing benzene production paths from ethylene and jet A1 fuel. However, they did not study naphthalene production paths which have been shown to have an impact on soot precursors [24] Raj et al. [25] included notably the benzyl+propargyl pathway in a toluene reference fuels (TRF) mechanism (nheptane/iso-octane/toluene) and modeled PAH formation up to pyrene in n-heptane/toluene and iso-octane/toluene diffusion flames. Zhang et al. [5] focused exclusively on benzene production in gasoline and kerosene flames but did not discuss the abovementioned naphthalene production paths. Blanquart et al. [26,27] and Wang et al. [10] included phenyl+vinylacetylene and cyclopentadienyl recombination pathways in their mechanisms but their study was restricted to TRF surrogates. Overall, the vast majority of detailed kinetic mechanisms of liquid transportation fuel combustion and PAH formation do not account for low temperature chemistry $[28,29]$ thereby preventing their direct application to the design of emerging IC engine technologies [30,31].

In the present work, a new detailed chemical kinetic mechanism for the combustion of a multipurpose liquid transportation fuel surrogate mixture including both low and high temperature chemistry was developed and validated over a wide range of operating pressures, temperatures, equivalence ratios, dilution and compositions. For the first time, three alternative naphthalene production paths, namely benzyl+propargyl, phenyl+vinylacetylene and dibenzofuran oxidation, were simultaneously considered in the same detailed kinetic mechanism, which allowed us to assess the impact of fuel formulation on the respective importance of naphthalene production pathways. The sequential occurrence of these paths was thereby evidenced and characterized. 


\section{Model development}

\subsection{Surrogate fuel formulation}

Due to high complexity of liquid transportation fuels, surrogate mixtures composed of few hydrocarbons (from two to a dozen of components [32]) are often used to represent them. To reduce computational time (strongly dependent on the number of species to be transported) and simplify as much as possible the analysis and design of ever more complex engine technologies, combustionists desperately need flexible, simple and reliable chemical surrogate mixtures. As for most of the computational fluid dynamics (CFD) models, evaporation surrogates and chemical surrogates are still distinct, the choice was made to focus on the development of a purely chemical surrogate. A complete physico-chemical surrogate accounts for a number of important targets including $\mathrm{H} / \mathrm{C}$ ratio, average molecular weight, autoignition quality, heat release rate, extinction, flame adiabatic temperature, sooting behavior, etc. A variety of surrogates formulations were proposed in the literature [33-37], but there is no one that models liquid transportation fuels with the same 3 components by varying their respective concentrations as a function of fuel type. The present ternary chemical surrogate does not aim to reproduce volatility nor H/C ratio nor PIONA (n-Paraffin, Iso-paraffin, Olefin, Naphthene, and Aromatic) composition, it was optimized to reproduces CN and TSI parameters accounting for both autoignition and soot production rate. We herein assess the robustness of this approach and PAHs formation during liquid transportation fuels combustion. Yang et al. [38] proposed that two global combustion parameters, namely the derived cetane number (DCN) and the threshold sooting index (TSI), could be considered for formulating a chemical surrogate. Based on these two global parameters, we considered a chemical surrogate for transportation fuels combustion composed of 3 components: iso-octane, $\mathrm{n}$-decane and n-propylbenzene. The fractions of components in the surrogate mixture are provided in Table 1.

\begin{tabular}{|l|c|c|c|}
\hline & $\begin{array}{c}\text { Diesel surrogate } \\
(\% \text { vol. })\end{array}$ & $\begin{array}{c}\text { Jet-A1 surrogate } \\
(\% \text { vol. })\end{array}$ & $\begin{array}{c}\text { Gasoline surrogate } \\
(\% \text { vol. })\end{array}$ \\
\hline n-decane & 61.6 & 53.2 & 5.0 \\
\hline Iso-octane & 0.3 & 21.6 & 75.0 \\
\hline $\begin{array}{l}\text { n-propyl- } \\
\text { benzene }\end{array}$ & 38.1 & 25.2 & 20.0 \\
\hline
\end{tabular}




\begin{tabular}{|l|c|c|c|c|c|c|}
\hline & Diesel & $\begin{array}{c}\text { Diesel } \\
\text { surrogate }\end{array}$ & Jet-A1 & $\begin{array}{c}\text { Jet-A1 } \\
\text { surrogate }\end{array}$ & Gasoline & $\begin{array}{c}\text { Gasoline } \\
\text { surrogate }\end{array}$ \\
\hline CN & 49.0 & 53.7 & 46.0 & 48.3 & 17.0 & 15.9 \\
\hline TSI & 28.0 & 26.9 & 21.4 & 20.0 & 16.0 & 17.3 \\
& {$[39]$} & & {$[40]$} & & {$[39]$} & \\
\hline
\end{tabular}

Table 1 : Surrogate fuels formulation to represent real fuels.

In terms of fuel composition representativity, $\mathrm{n}$ - and iso-paraffins are massively present in all liquid transportation fuels $[34,41]$. Aromatic compounds are also usually present in petroleum-based liquid transportation fuels $[34,41,42]$ and have to be included in the blend to predict correctly soot volume fraction produced in fossil distillates combustion. N-propylbenzene was chosen as a good trade-off between light and heavier aromatics (from benzene to methylnaphthalene). Moreover, the combustion chemistry of n-decane, iso-octane and n-propylbenzene is presently relatively well modeled and several kinetic mechanisms have been validated over a wide range of conditions [43].

\subsection{Development of a detailed chemical kinetic mechanism}

A new detailed chemical kinetic mechanism describing the combustion of our and literature surrogates was derived from different subsets. Iso-octane and n-decane sub-mechanisms were extracted from Dooley et al. [33] and n-propylbenzene sub-mechanism comes from the study of Darcy et al. [31]. These 3 sub-mechanisms were merged to build a base mechanism. Whenever several thermokinetic data were present for the same reaction in both individual sub-mechanisms, those of Dooley et al. [33] were retained. The $\mathrm{C}_{0}, \mathrm{C}_{1}, \mathrm{C}_{2}$ and $\mathrm{C}_{3}$ sub models were extracted directly from the mechanism of Dooley et al. [33]. Reactions were subsequently added to improve agreement with experimental data obtained over a broad range of conditions such as ignition delay times, laminar flame speeds, PAH and important $\mathrm{C}_{1}-\mathrm{C}_{6}$ intermediates concentration profiles. Table 2 summarizes all mechanisms used for the model construction. 


\begin{tabular}{|l|l|}
\hline \multicolumn{1}{|c|}{ Mechanisms } & \multicolumn{1}{c|}{ Subsets } \\
\hline Dooley et al. [33] & $\begin{array}{l}\text { n-decane and iso-octane subsets including } \\
\mathrm{H}_{2} / \mathrm{CO}, \mathrm{C}_{1}-\mathrm{C}_{6} \text { subsets }\end{array}$ \\
\hline Darcy et al. [31] & $\mathrm{n}$-propylbenzene subset \\
\hline Alzueta et al. [44] & $\mathrm{C}_{2}$ subset \\
\hline Metcalfe et al. [45] & $\mathrm{C}_{2}$ subset \\
\hline Hansen et al. [46] & $\mathrm{C}_{3} / \mathrm{C}_{4}$ subset \\
\hline Colket et al. [17,47] & $\mathrm{C}_{4} / \mathrm{C}_{6}$ subset \\
\hline Wang et al. [48] & $\mathrm{C}_{4} / \mathrm{C}_{6}$ subset \\
\hline Zeng et al. [49] & $\mathrm{C}_{4} / \mathrm{C}_{6}$ subset \\
\hline Ranzi et al. [50] & n-decane/iso-octane low temperature reactions \\
\hline Yuan et al. [51] & $\begin{array}{l}\text { Monoaromatics (toluene, styrene, } \\
\text { phenylacetylene) subset }\end{array}$ \\
\hline $\begin{array}{l}\text { Yuan et al. [51], Slavinskaya et al. [52], Miyoshi } \\
\text { et al. [53], Norinaga et al. [54], Kousoku et al. } \\
\text { [55] and Djokic et al. [56] }\end{array}$ & PAH up to coronene subset \\
\hline
\end{tabular}

Table 2 : Mechanistic sources for model construction

Reactions added for improving $\mathrm{C}_{2}$ species (acetylene, ethylene, ethane) formation were taken from Alzueta et al. [57] and from AramcoMech [45]. For $\mathrm{C}_{3}$ species (allene, propyne, propene), additional reactions were taken from Hansen et al.[46]. For $\mathrm{C}_{4} / \mathrm{C}_{6}$ species (butadienes, butenes, cyclopentadiene, benzene), reactions were taken from Wang et al. [48], Zeng et al. [49] and Colket et al. [47]. In addition to low temperature reactions from Dooley et al. [33], some additional n-heptane, iso-ocatne and n-decane low temperature reactions were extracted from the work of Ranzi et al. [50]. This low temperature subset allowed to improve ignition delay times predictions over the $600-900 \mathrm{~K}$ range, which is crucial in Diesel engine operation. For monoaromatic species (toluene, styrene, phenylacetylene), reactions were taken from Yuan et al. [58]. The PAH subset (up to coronene and including polyphenyls) was built from the works of Yuan et al. [58], Slavinskaya et al. [52], Miyoshi et al. [53], Norinaga et al. [54], Kousoku et al. [59] and Djokic et al. [56]. In the present reaction model, dibenzofuran subset was taken from Ranzi et al. [60] and from Sebbar et al. [61] as shown in

Table 3.

\begin{tabular}{|l|l|l|l|l|}
\hline Reactions & A $\mathbf{( c m}, \mathbf{~ m o l}, \mathbf{s})$ & \multicolumn{1}{|c|}{$\mathbf{n}$} & \multicolumn{1}{|c|}{ E $\mathbf{( k c a l / m o l})$} & \multicolumn{1}{c|}{ Ref } \\
\hline C6H5O+C6H5O=>DIBZFUR+H2O & $4.0 \times 10^{13}$ & 0.00 & 11.0 & {$[60]$} \\
\hline DIBZFUR+H=DIBZFURNYL+H2 & $2.5 \times 10^{14}$ & 0.00 & 16.0 & p.w \\
\hline DIBZFURNYL+O2=DIBZFURNOXY+O & $1.5 \times 10^{19}$ & -0.89 & 18.1 & {$[61]$} \\
\hline DIBZFUR+OH=>CO+NAPHT+HCO & $2.0 \times 10^{13}$ & 0.00 & 0.0 & {$[60]$} \\
\hline
\end{tabular}

Table 3 : Dibenzofuran submechanism used in the present work. 
Dibenzofuran (DIBZFUR) is produced from phenoxy radicals recombination and may be consumed through $\mathrm{H}$ abstraction or oxidation by $\mathrm{OH}$. The rate constant of phenoxy recombination is in line with theoretical and experimental data published so far. The rate constant for $\mathrm{H}$ abstraction from dibenzofuran to yield dibenzofuranyl was herein assumed to be identical to that of $\mathrm{H}$ abstraction from naphthalene. Benzene oxidation in moderately rich flames can yield significant quantities of resonantly stabilized phenoxy radicals (> $10 \mathrm{ppm}$ ) [62] which readily recombine to dibenzofuran [63]. This reaction path has been so far studied mainly in the context of oxygenated fuel oxidation. The rate constant from Ranzi et al. [60] mechanism adopted in the present study is smaller by a factor of two than Grotheer et al. rate constant [64]. Further, it is in good agreement with the Gibbs free energy of activation obtained by Asatrya et al. [63] in their electronic structure calculations of phenoxy dimer dehydration. As there is not sufficient experimental data to directly validate dibenzofuran path kinetics in jet A premixed flames, we assessed this path against dibenzofuran oxidation experiments in very diluted conditions, showing a correct agreement of naphthalene concentration profile with measurements from [22]. This tends to indicate that the contribution of this path to naphthalene production is indeed correctly accounted for by the present kinetic model at $\mathrm{T}>1000 \mathrm{~K}$.

The $\mathrm{C}_{0}-\mathrm{C}_{1}$ subset contains 34 species and 171 reactions. The $\mathrm{C}_{2}-\mathrm{C}_{3}$ subset contains 96 species and 582 reactions. The $\mathrm{C}_{4}-\mathrm{C}_{5}$ subset contains 210 species and 1170 reactions. The $\mathrm{C}_{6}-\mathrm{C}_{7}$ subset contains 196 species and 770 reactions. The $\mathrm{C}_{8}-\mathrm{C}_{9}$ subset contains 192 species and 856 reactions. The $\mathrm{C}_{10}-\mathrm{C}_{11}$ subset contains 132 species and 487 reactions. The $\mathrm{C}_{12+}$ subset contains 154 species and 514 reactions. To allow compatibility of the present mechanism with older chemkin versions, pressure dependency has been described using Troe's formalism. The vast majority (98\%) of reactions implemented in the mechanism are bidirectional. Some lumped reactions were assumed to be monodirectional as $\Delta \mathrm{rG} \ll<0$ over the whole temperature range of interest $(300-2500 \mathrm{~K})$ and because making them bidirectional may result in convergence issues for premixed flame calculations. The most important added reaction kinetic parameters based on sensitivity analyses performed for benzene and naphthalene are listed in Table 4. 


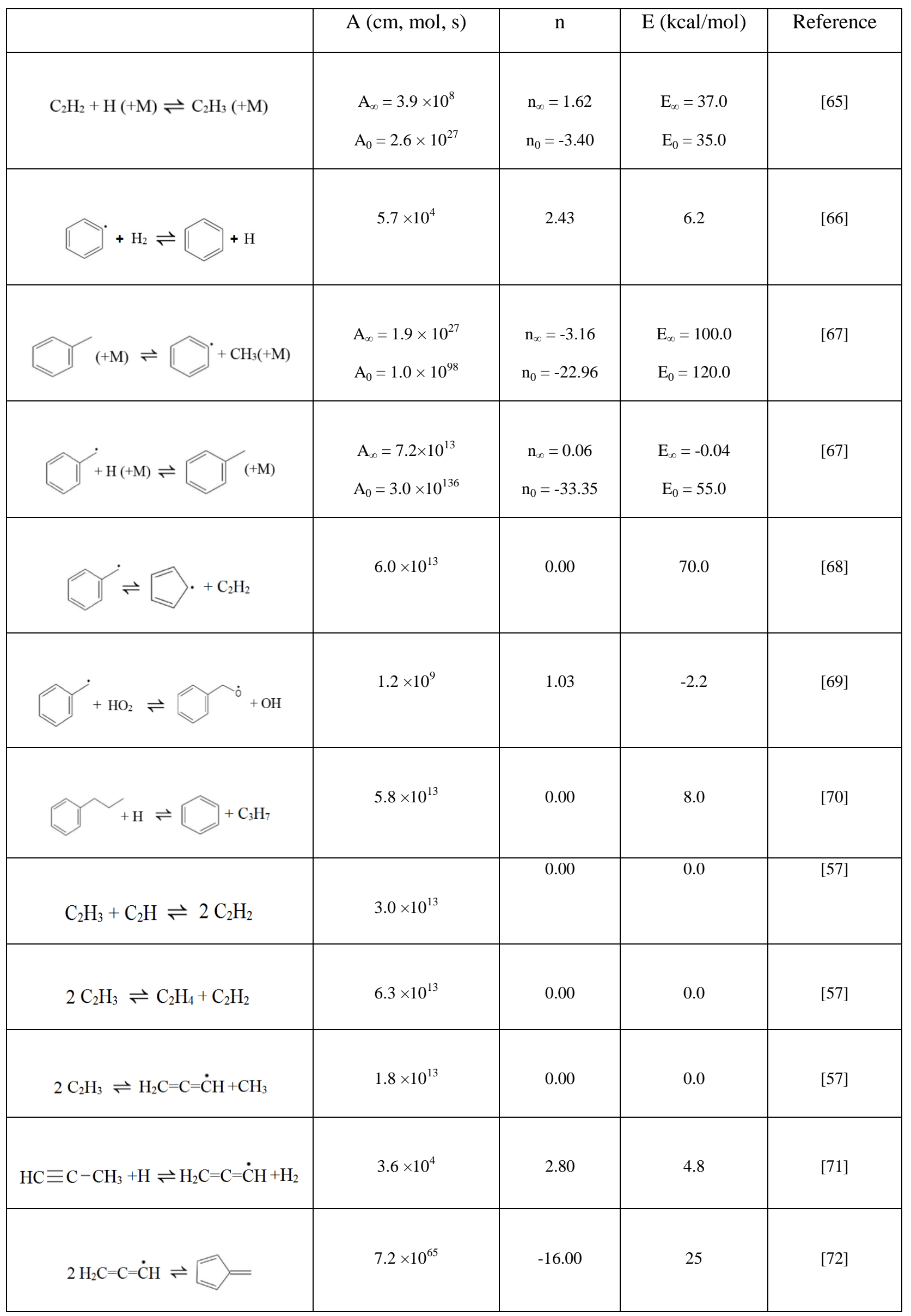




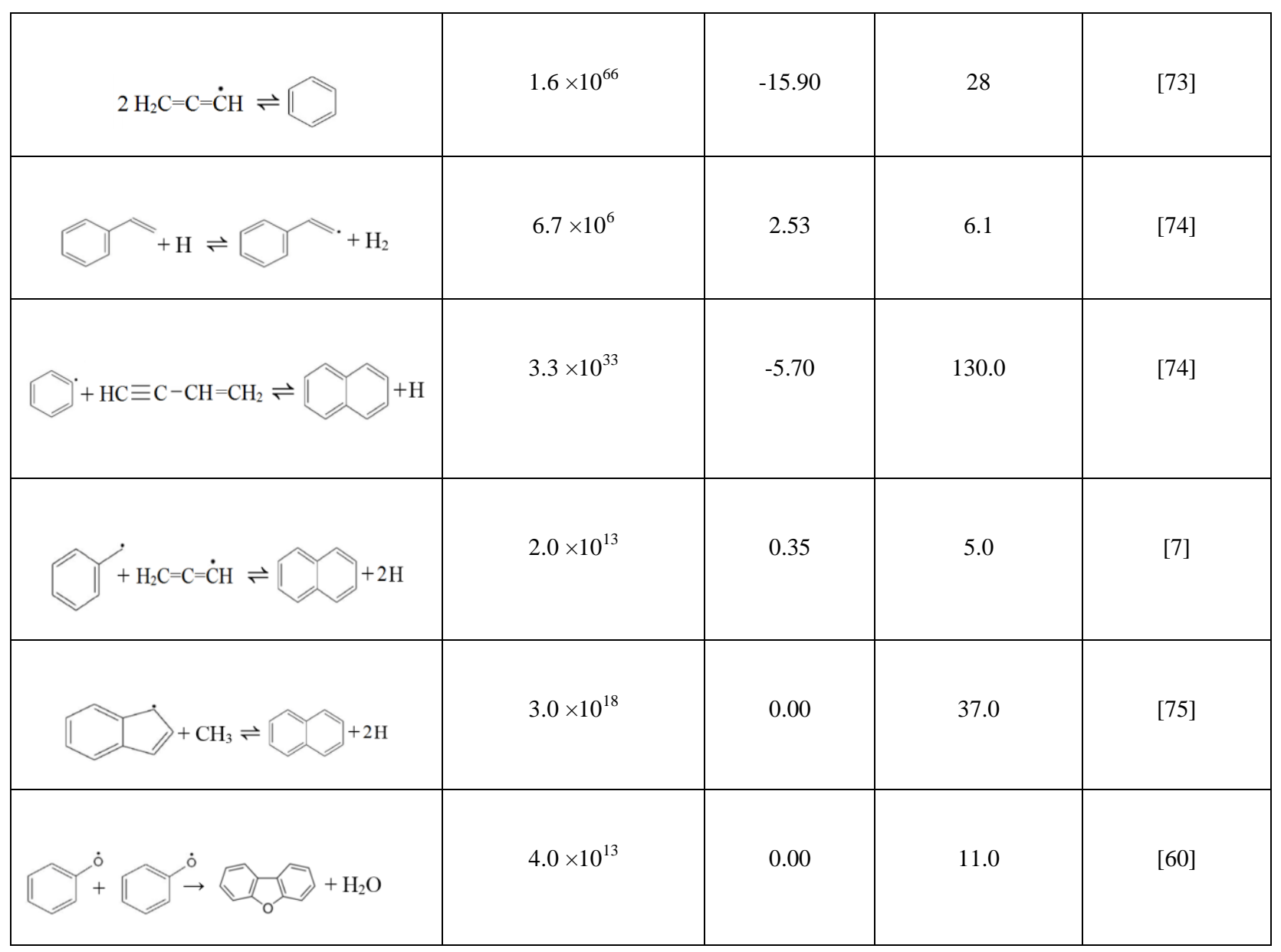

Table 4 : Kinetic rate parameters $\left(k=\mathrm{A}(\mathrm{T} / 1 \mathrm{~K})^{\mathrm{n}} \exp (-\mathrm{E} / \mathrm{RT})\right)$ of most important added reactions for naphthalene production.

To better account for diesel intermediate temperature oxidation, the rate parameters of the reaction between benzyl and hydroperoxy radical forming benzoxyl radical (see Table 4), which is important from 800 to $1000 \mathrm{~K}$, were modified. Despite modest deviation with other proposed rate constants [26,31,69,76], that of Da Silva et al. [69] results in a better agreement with experimental ignition delays. In the present work, phenyl+vinylacetylene and benzyl+propargyl pathways are represented as lumped reactions. In fact, production of naphthalene from these two pathways proceed respectively through the formation of phenyl vinylacetylenyl [77] and methyleneindanyl [78]. Fig.1 shows the rate constants proposed for phenyl+vinylacetylene and benzyl+propargyl reactions yielding naphthalene. 

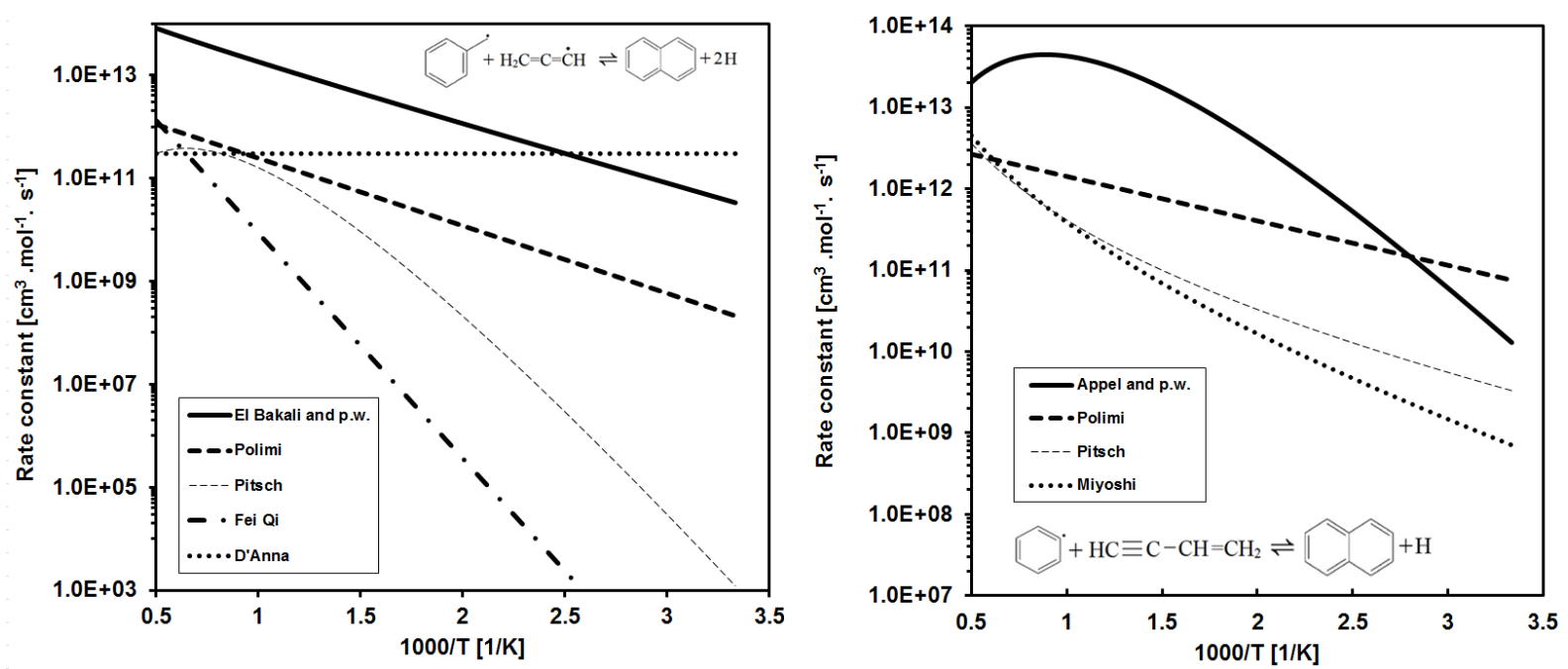

Fig.1. The proposed rate constants for phenyl+vinylacetylene and benzyl+propargyl reactions. Units are in mol, s, $\mathrm{cm}^{3}$,cal, $\mathbf{K}$.

The rate constant herein adopted for phenyl+vinylacetylene pathway follows the recommendation of Appel et al. [8] exhibiting a negative curvature unlike that recommended by Miyoshi et al. [53]. For benzyl+propargyl reaction, large discrepancies still subsist between recommended rate parameters. The rate constant proposed previously by one of the authors [79] was used. The final mechanism contains 1014 species and 4550 most reversible reactions and also accounts for both low and high temperature combustion regimes. This mechanism, including thermochemical and transport data, is available as a supplementary material. Kinetic modeling was performed with the PREMIX and AURORA libraries of Chemkin-PRO package, version 15131 [80]. For all premixed flames calculations, gradient and curvature criteria for mesh refinement were set both to 0.1 and a mixtureaveraged transport approach was used as the full multi-component formulation was too computationally intensive for the present mechanism.

It is important to emphasize that all calculations were exclusively limited to the gas phase. Therefore, the computed mole fraction profiles of some specific species that will be shown in the next section can evolve when the present mechanism will be integrated to the soot code. This evolution will highly depend on the degree of species involvement in the nucleation process. Thus it is reasonable to expect a significant pyrene mole fraction reduction (especially in the post flame region) if its selfcondensation is maintained as a key step in the particle inception process. The ongoing work on modeling of soot volume fraction based on the sectional method which incorporates the present gas- 
phase mechanism with new precursors of nucleation processes should provide answers on these impacts.

\section{Results and Discussion}

\subsection{Mechanism validation}

The performance of the final mechanism was assessed against experimental data and several major mechanisms from the literature (see figures for references). A wide range of experimental conditions involving both pure components and commercial fuels combustion have been considered in validating the mechanism. Some results obtained are shown in this section and in supplementary data. Table 5 presents an overview of experimental data used for model validation and Table 6 provides information of those reaction models included in comparison of species profiles taken from literature, with number of species and reactions and their range of validation.

\begin{tabular}{|c|c|c|}
\hline Fuel structure & Configuration & Reference \\
\hline Acetylene & Oxidation in Plug flow reactor, $1 \mathrm{~atm}, \Phi=7.50$ & [57] \\
\hline Ethylene & Premixed laminar flame , $1 \mathrm{~atm}, \Phi=3.06$ & [13] \\
\hline N-butane & Premixed laminar flame, $1 \mathrm{~atm}, \Phi=2.16$ & [7] \\
\hline Benzene & Premixed laminar flame, 30 Torr, $\Phi=2.00$ & [81] \\
\hline Iso-octane & Premixed laminar flame, $1 \mathrm{~atm}, \Phi=1.90$ & [11] \\
\hline N-decane & Premixed laminar flame, $1 \mathrm{~atm}, \Phi=1.70$ & [82] \\
\hline Styrene & Premixed laminar flame, 30 Torr, $\Phi=1.70$ & [83] \\
\hline Ethylbenzene & Premixed laminar flame, 30 Torr, $\Phi=1.79$ & [84] \\
\hline N-propylbenzene, & Premixed laminar flame, 30 Torr, $\Phi=1.79$ & [48] \\
\hline \multicolumn{3}{|l|}{ Gasoline } \\
\hline & Premixed laminar flame, 30 Torr, $\Phi=1.73$ & [85] \\
\hline & Ignition delay times $20-40$ bar & [86] \\
\hline & Laminar flame speeds, $\Phi=0.50-1.50$ & [87] \\
\hline \multicolumn{3}{|l|}{ Jet Fuel } \\
\hline & Premixed laminar flame, $1 \mathrm{~atm}, \Phi=1.70$ & {$[82]$} \\
\hline & Oxidation in jet stirred reactor, $1 \mathrm{~atm}, \Phi=2.00$ & [29] \\
\hline & Ignition delay times $20 \mathrm{~atm}$ & [88] \\
\hline & Laminar flame speeds, $\Phi=0.70-1.40$ & [89] \\
\hline \multicolumn{3}{|l|}{ Diesel Fuel } \\
\hline & Oxidation in jet stirred reactor, $1 \mathrm{~atm}, \Phi=2.00$ & [37] \\
\hline & Ignition delay times $6 \mathrm{~atm}$ & [90] \\
\hline & Laminar flame speeds, $\Phi=0.70-1.50$ & [91] \\
\hline
\end{tabular}

Table 5 : The overview of experimental data used for model validation. 


\begin{tabular}{|l|l|l|}
\hline $\begin{array}{l}\text { Reaction models from } \\
\text { literature }\end{array}$ & Number of species/reactions & Range of validation \\
\hline Polimi [60] & 200 species 6826 reactions & $\begin{array}{l}\text { Gasoline, Jet Fuels, Diesel: } \\
\text { PRFs, heavy n-alkanes, } \\
\text { Isocetane, Decalin, Tetralin }\end{array}$ \\
\hline Battin_Leclerc et al. [92] & 662 species and 3884 reactions & $\begin{array}{l}\alpha \text {-methylnaphthalene/air and } \alpha- \\
\text { methylnaphthalene/n-decane/air } \\
\text { mixtures }\end{array}$ \\
\hline Yuan et al. [83] & 290 species and 1786 reactions & Styrene flames \\
\hline Dooley et al. [33] & 1599 species and 6633 reactions & Jet fuel surrogate \\
\hline Raj et al. [25] & 231 species and 1350 reactions & Gasoline surrogate fuels \\
\hline LLNL [93] & $\begin{array}{l}\text { 2885 species and 11,754 } \\
\text { reactions }\end{array}$ & Diesel fuel surrogate \\
\hline
\end{tabular}

Table 6: Models included in the validation process against experiments.

Modeling results were compared to experimental data previously published on a few atmospheric premixed flames of ethylene $(\varphi=3.0)$ [13], jet fuel $(\varphi=1.7)$ [82], isooctane $(\varphi=1.9)$ [11], n-decane ( $\varphi=1.7)$ [82], n-butane $(\varphi=2.1)$ [7] and a 30 Torr premixed flame of gasoline $(\varphi=1.7)$ [85] as well as styrene $(\varphi=1.7)$ [83], n-propylbenzene $(\varphi=1.8)$ [48], benzene $(\varphi=2.0)$ [94] and ethylbenzene $(\varphi=1.8)$ [95] flames. In jet stirred reactor configuration, diesel fuel oxidation $(\varphi=1.5)$ [37] at a pressure of 10 bar was modeled. The prediction of ignition delays times and laminar flame speeds of gasoline [86], jet-A1 fuel [88] and diesel fuel [90] was also considered. Results obtained for a variety of other fuels are provided in supplementary material. 

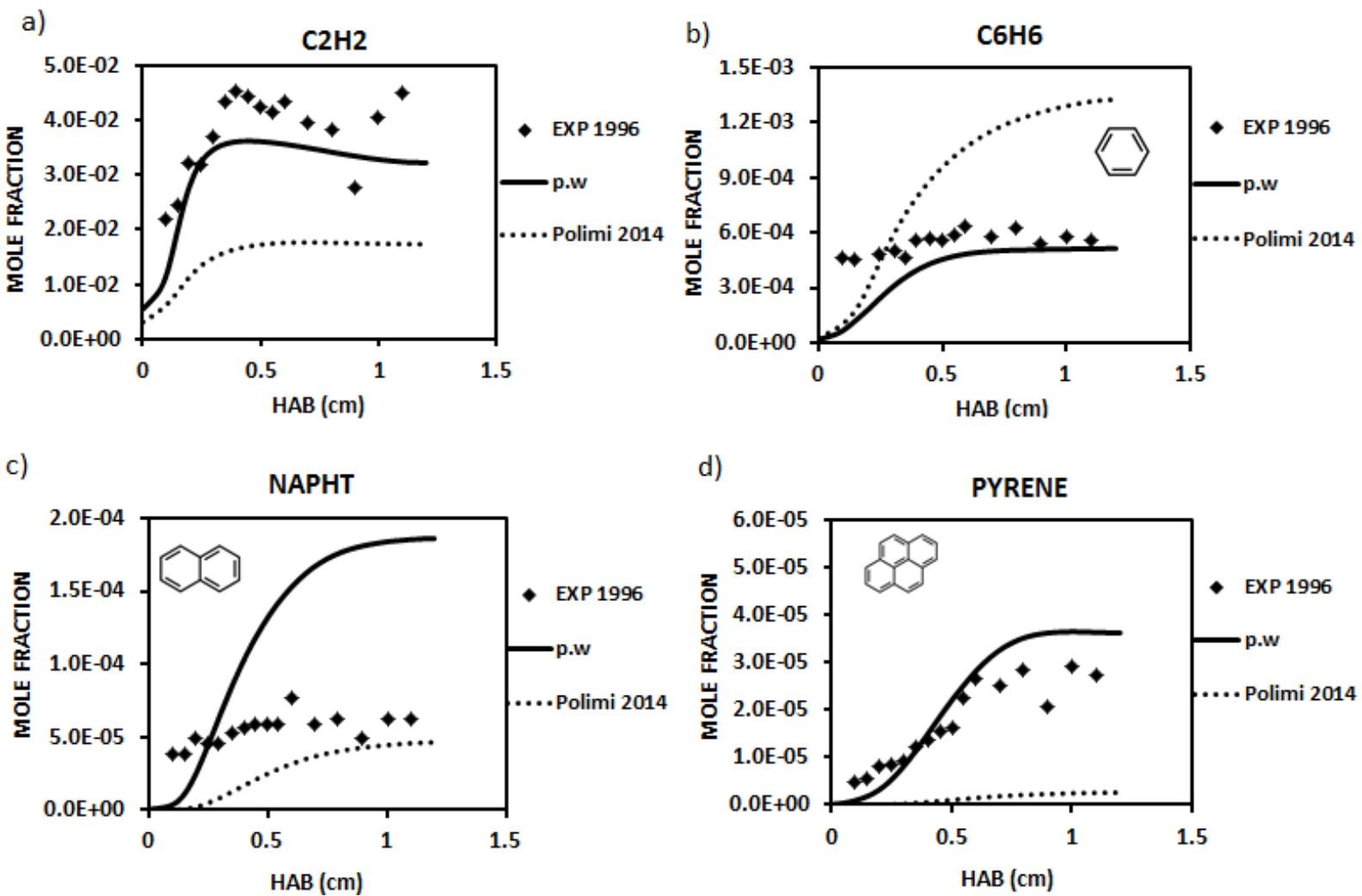

Fig.2. Predicted and experimental mole fractions of a): acetylene, b): benzene, c): naphthalene (NAPHT) and d): pyrene in ethylene premixed flame $(\varphi=3.0 ; P=1$ atm $)$. The symbols represent the experimental data [13]; the continuous lines represent the modeling results from the present work; dotted lines: Polimi mechanism[60].
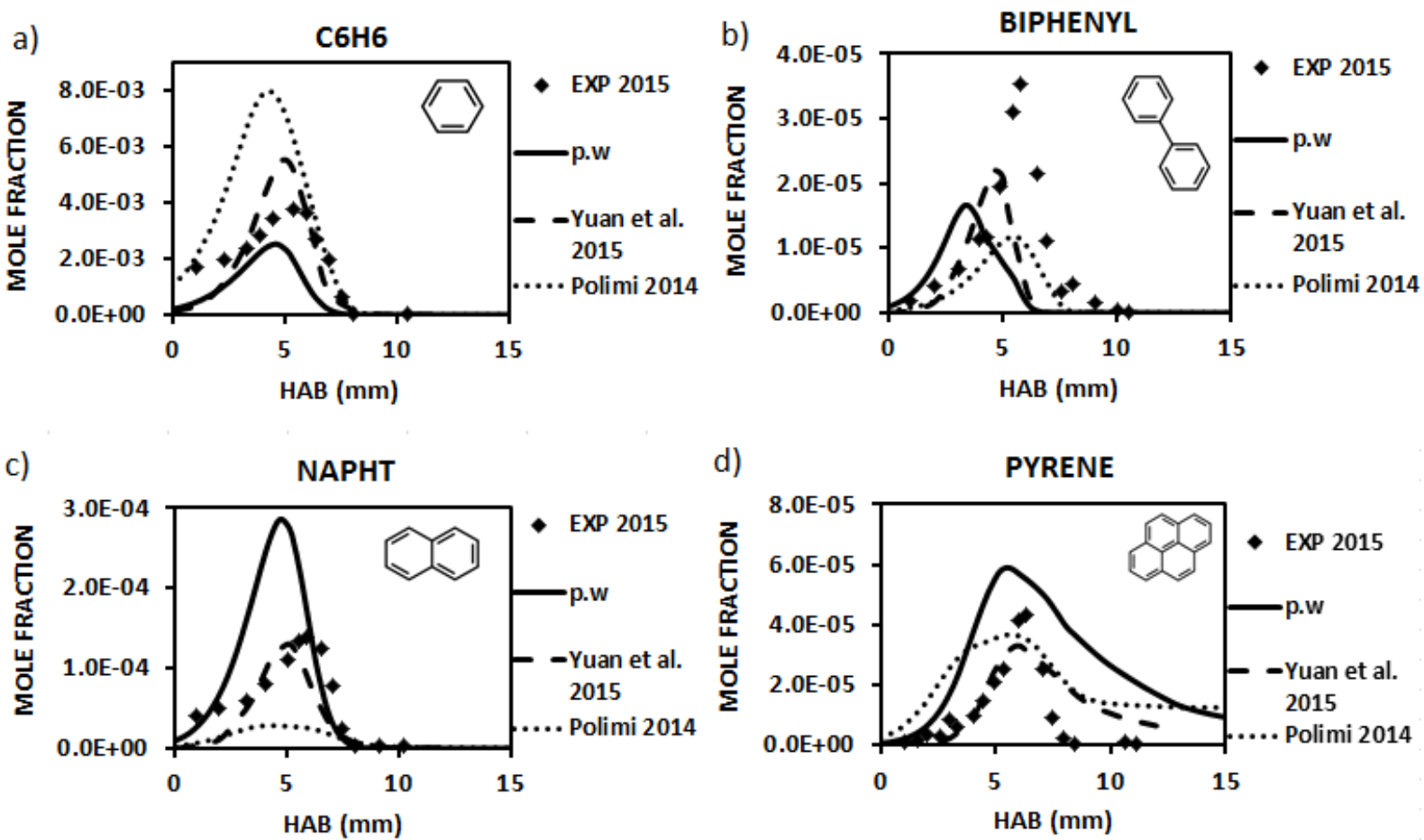

Fig.3. Predicted and experimental mole fractions of a): benzene, b): biphenyl, c): naphthalene and d): pyrene in styrene premixed flame $(\varphi=1.7 ; P=30$ Torr $)$. The symbols represent experimental data [83]; the continuous lines represent the modeling results from the present work; dashed lines: Yuan et al. mechanism [83] and dotted lines: Polimi mechanism[60]. 
a)

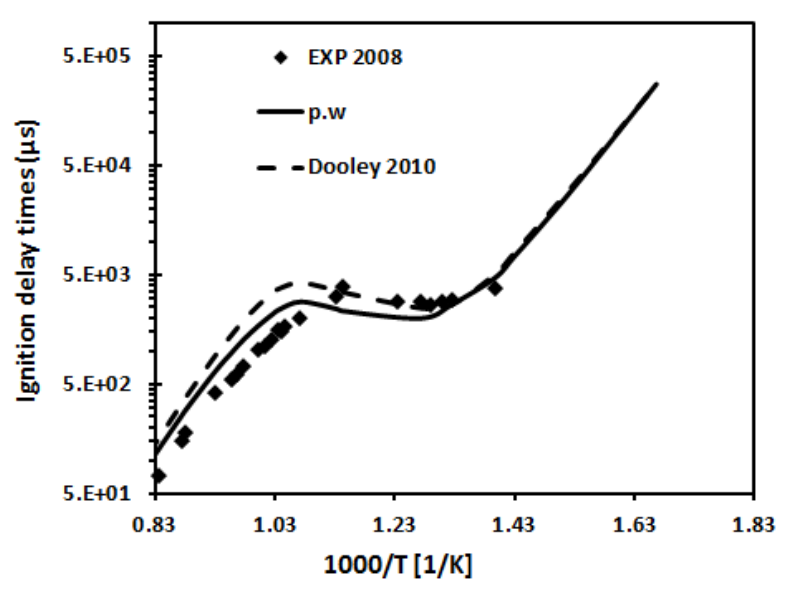

b)

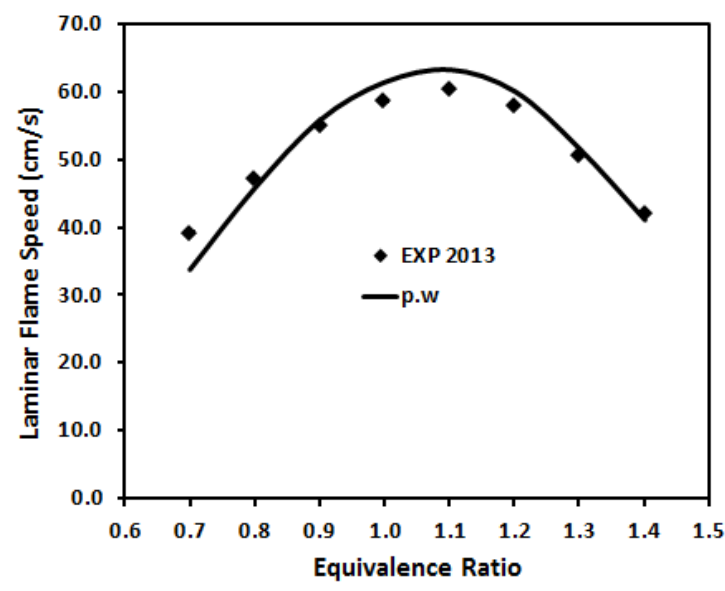

Fig.4. a): Jet fuel ignition delay times prediction, $\Phi=1 ; P=20 \mathrm{~atm} ; \mathrm{T}=6 \mathbf{6 0 0 - 1 2 3 0} \mathrm{K} ; \mathrm{X}_{\mathrm{fue}} / \mathrm{O}_{2} / \mathrm{N}_{2} \mathbf{1 . 3 \%} / 20.7 \% / 78.0 \%$ in mole fraction. The symbols represent experimental data from [88]; The continuous lines represent the modeling results from the present work; dashed lines: Dooley et al. mechanism $\left(\mathrm{nC}_{10} / \mathrm{iC}_{8} / \mathrm{Toluene}: 42.67 \%\right.$ $(\% \mathrm{~mol}) / 33.02 \% / 24.31 \%)$ [33]. b): Laminar burning velocity of jet $\mathrm{A}$ flame : $\mathrm{P}=1 \mathrm{~atm}$; Tu $=400 \mathrm{~K}$; The symbols represent experimental data from [89].

a)

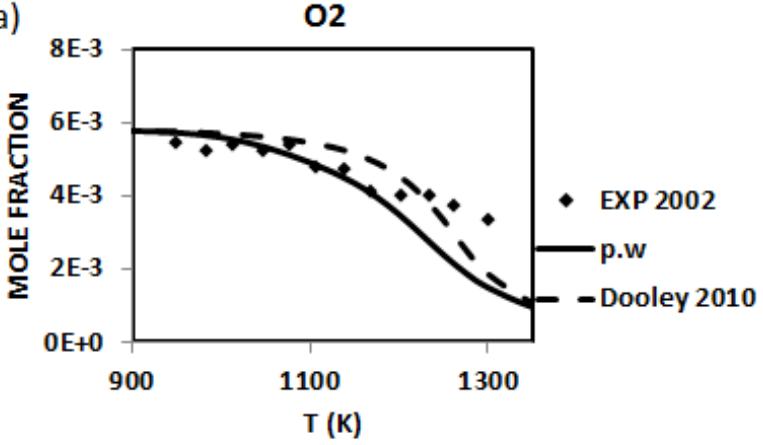

c)

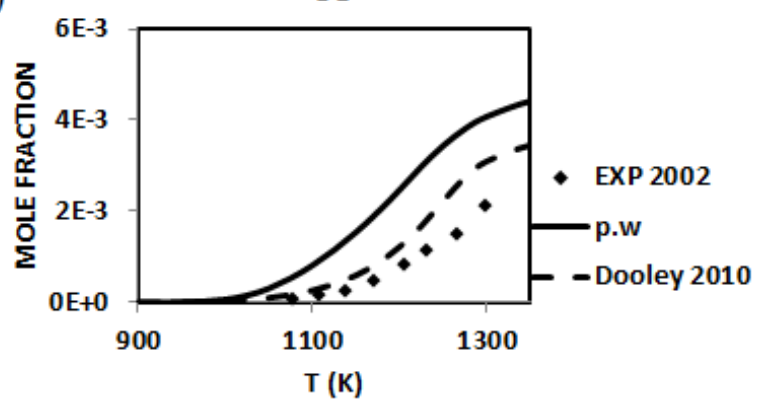

b)

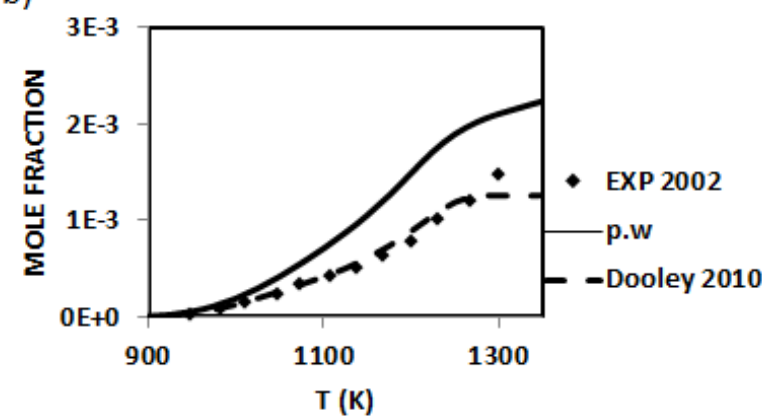

d)

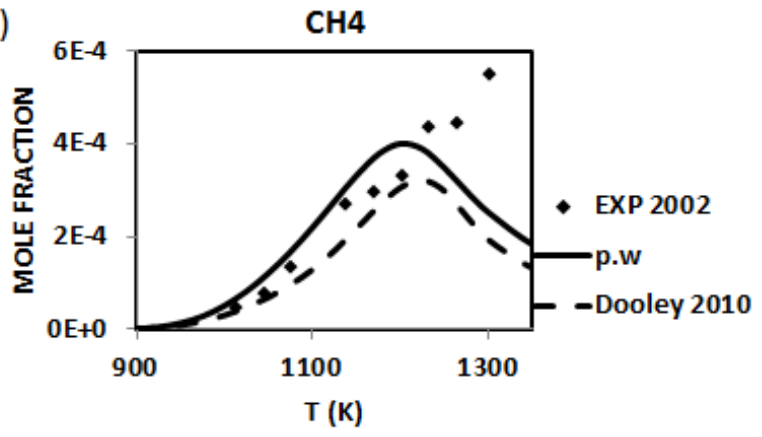


e)
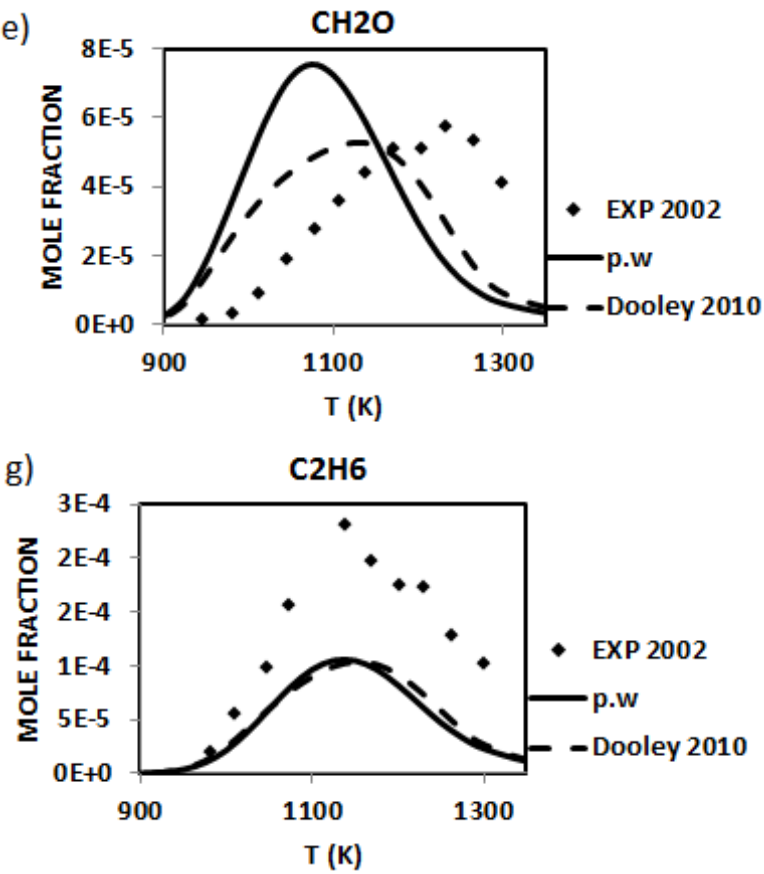

i)

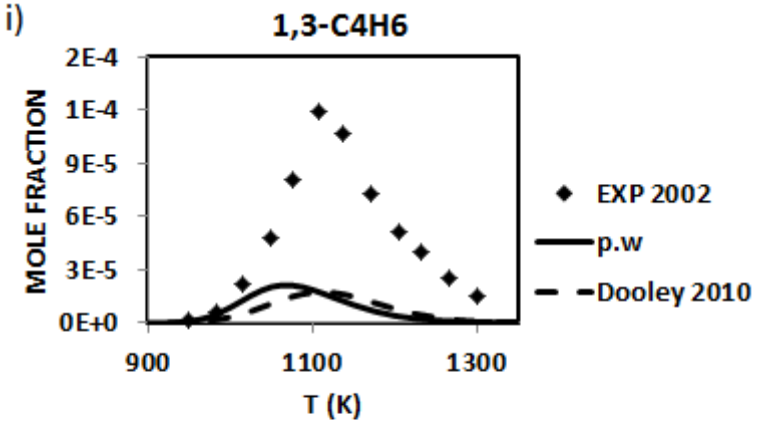

k)

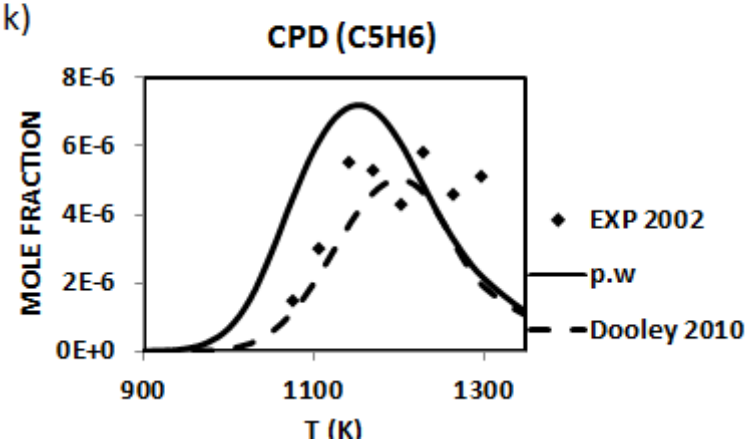

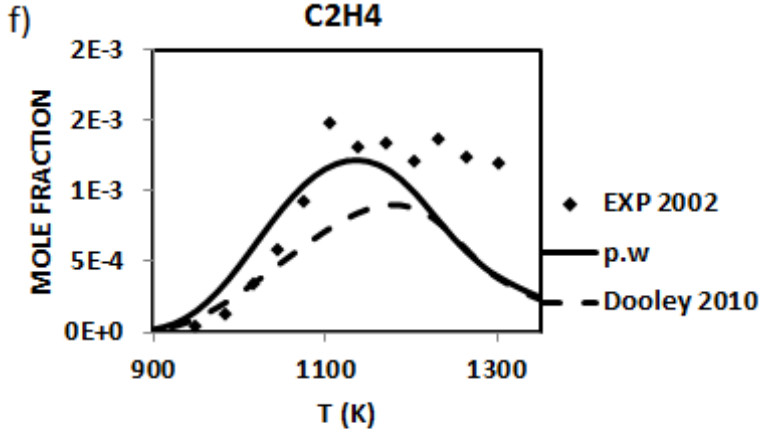

h)

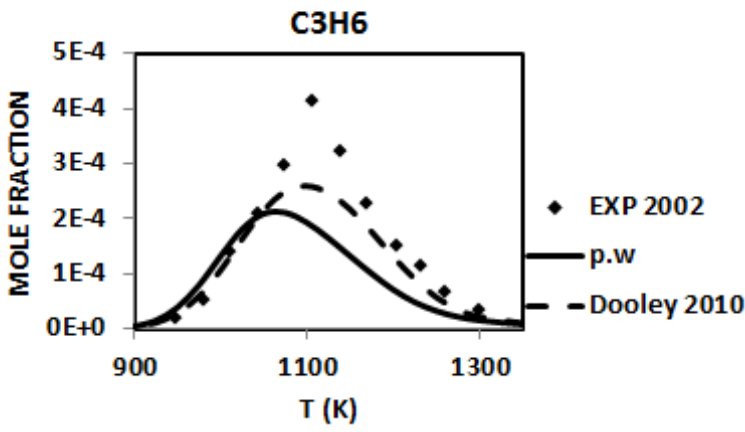

j)

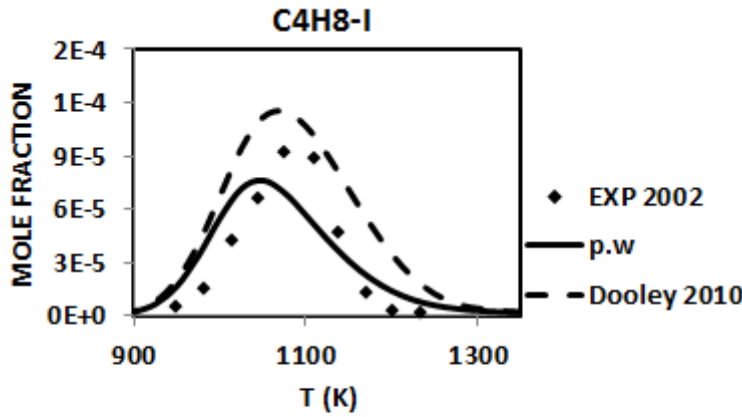

I)

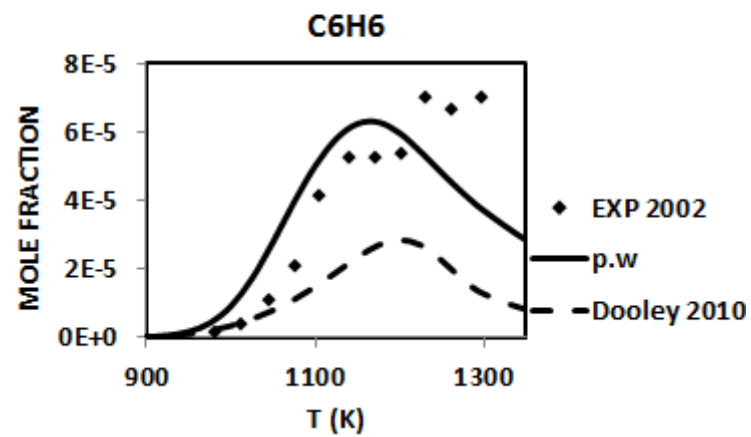




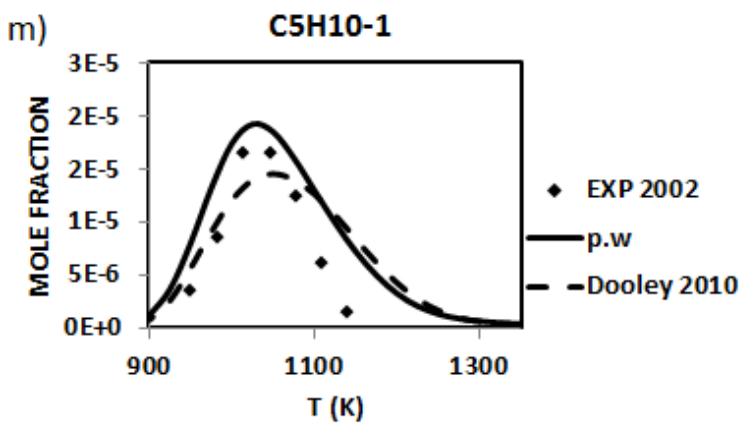

n)
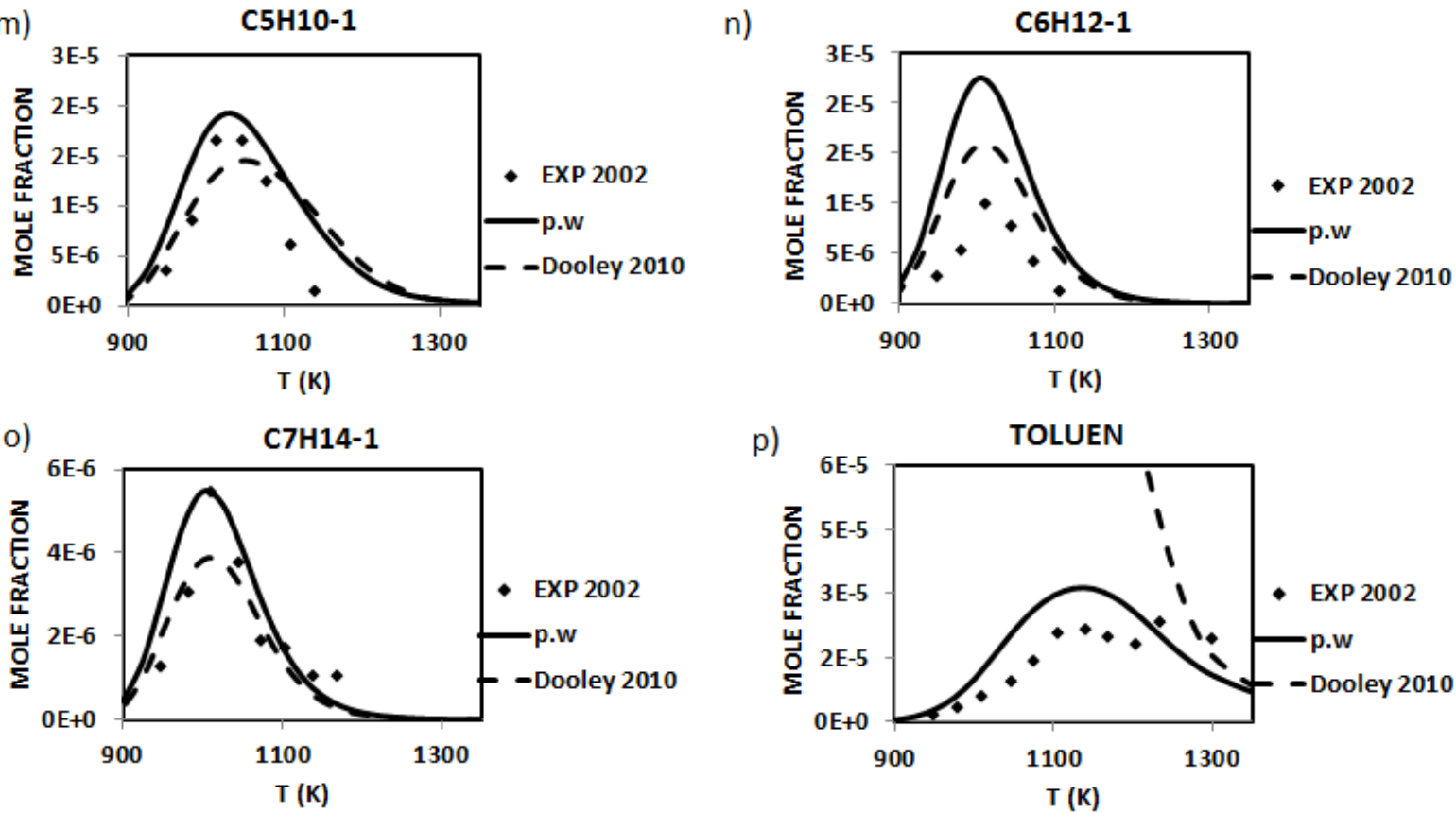

Fig.5. Jet fuel $\left(\mathrm{C}_{11} \mathrm{H}_{22}\right)$ diluted combustion in jet stirred reactor: jet fuel/ $\mathrm{O}_{2} / \mathrm{N}_{2}: 0.07 / 0.58 / 99.35$ in $\% \mathrm{~mol} . \varphi=2.0$; $\mathrm{P}=1 \mathrm{~atm} ; \boldsymbol{\tau}=0.07 \mathrm{~s}$; Predicted and experimental mole fraction of a): oxygen, $\mathrm{b}$ ): hydrogen, c): carbon monoxide, $\mathrm{d}$ ): methane, e): formaldehyde, f): ethylene, g): ethane, $h$ ): propene, i): 1,3-butadiene, $\mathrm{j}$ ): iso-butene, $\mathrm{k}$ ): cyclopentadiene, 1): benzene, m): 1-pentene, $n$ ): 1-hexene, o): 1-heptene, ): toluene. The symbols represent experimental data from [29]; the continuous lines represent the modeling results from the present work; dashed lines: Dooley et al. mechanism $\left(\mathrm{nC}_{10} / \mathrm{iC}_{8} /\right.$ Toluene : $\left.42.67 \%(\% \mathrm{~mol}) / 33.02 \% / 24.31 \%\right)[33]$.
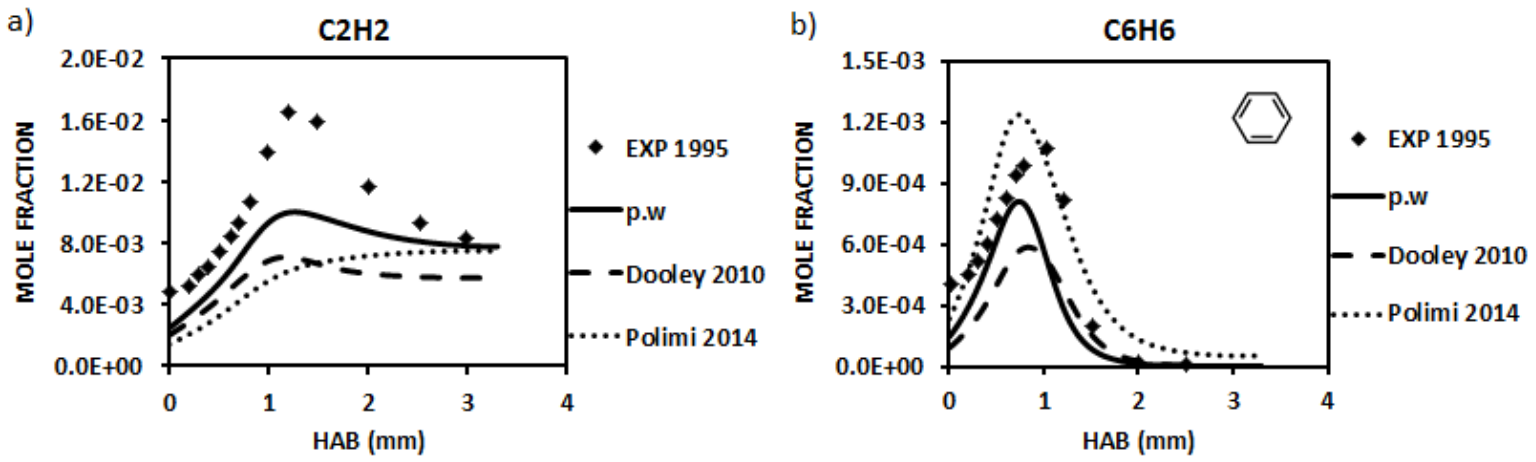

c)

d)
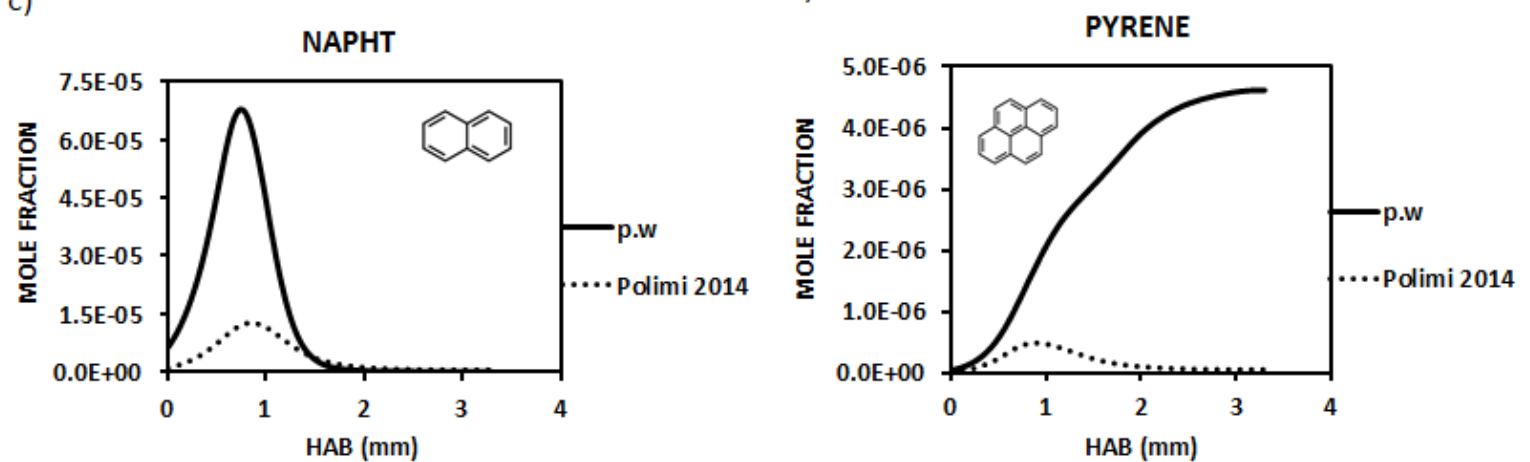

Fig.6. Predicted and experimental mole fractions of a): acetylene, b): benzene, c): naphthalene and d): pyrene in jet fuel premixed flame $(\varphi=1.7 ; P=1$ atm). The symbols represent experimental data [82]; the continuous lines represent the modeling results from the present work; dashed lines: jet surrogate mechanism from Dooley et al. [33] and dotted lines: Polimi mechanism[60]. 

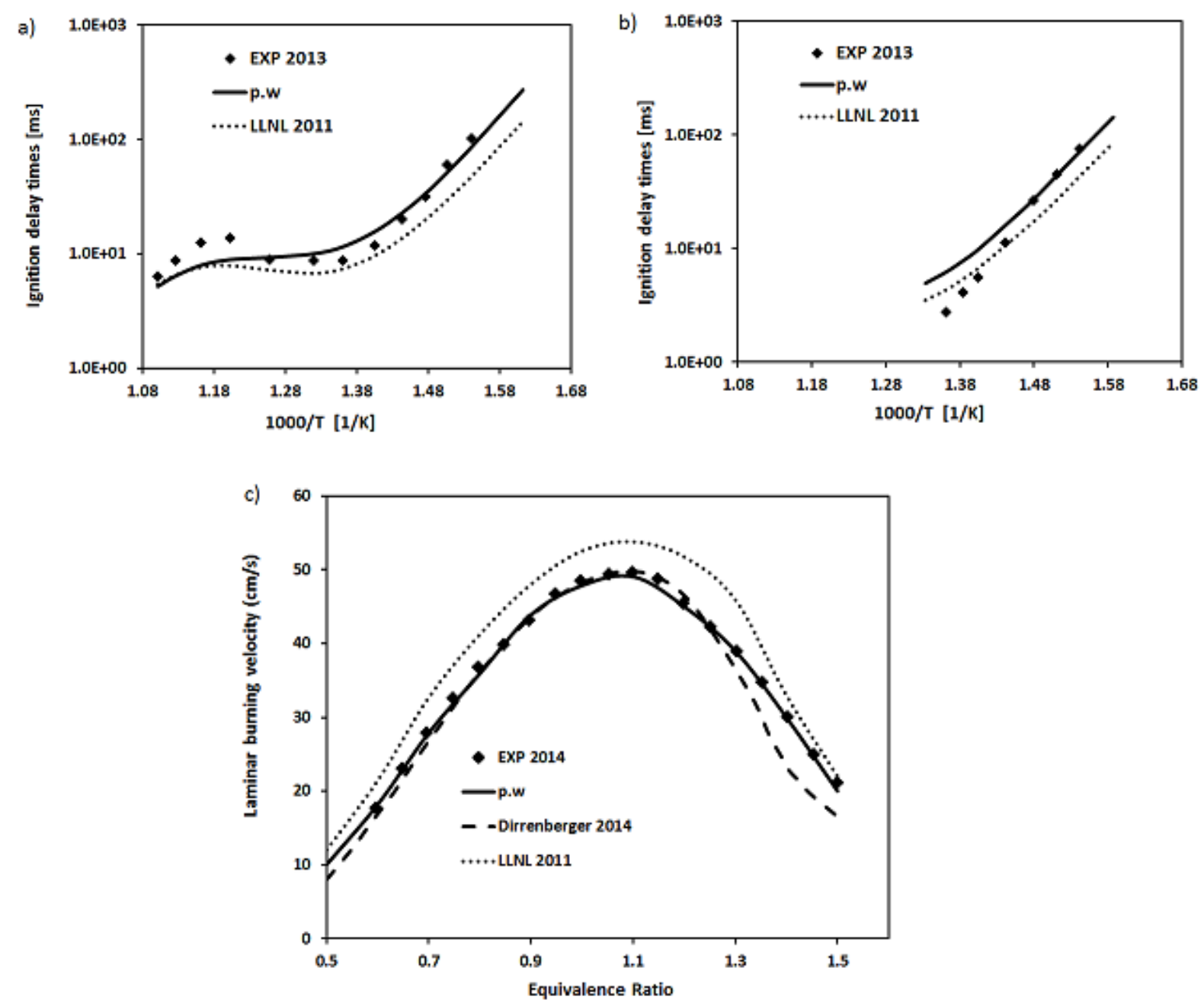

Fig.7. a): Ignition delay response of gasoline in a rapid compression machine: $\varphi=1 ; P=20 \mathrm{bar} ; \mathrm{T}=640-900 \mathrm{~K}$; The symbols represent experimental data from [86]; b): Ignition delay response of gasoline in a rapid compression machine: $\varphi=1 ; P=40$ bar ; $T=630-740 \mathrm{~K}$; The symbols represents experimental data from [86]; c): Laminar burning velocity of gasoline : $P=1 \mathrm{~atm} ; T_{u}=358 \mathrm{~K}$; The symbols represents experimental data from [87]; the continuous lines represent the modeling results from the present work; dashed lines: Dirrenberger et al. mechanism [87]; dotted lines: LLNL mechanism [96] (nC7/iC8/Toluene: 13.7\% (mol)/42.8\%/43.5\%, composition from [97]). 
a)

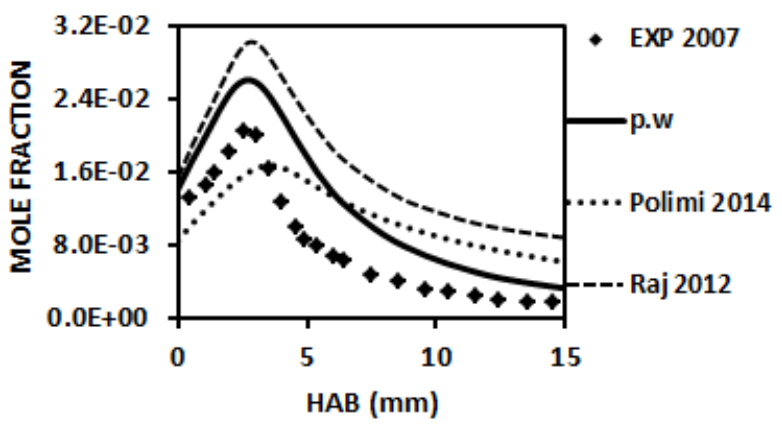

C

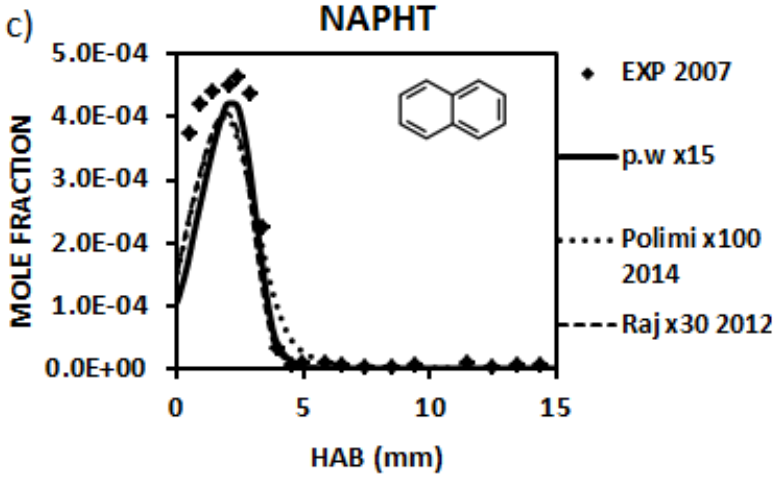

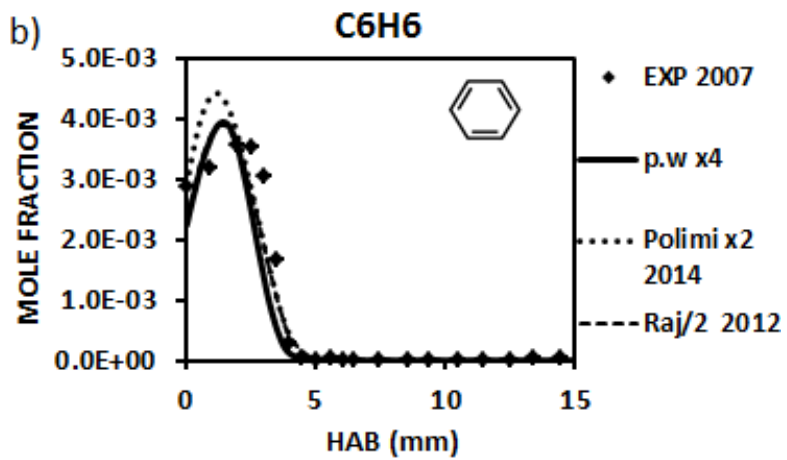

d)

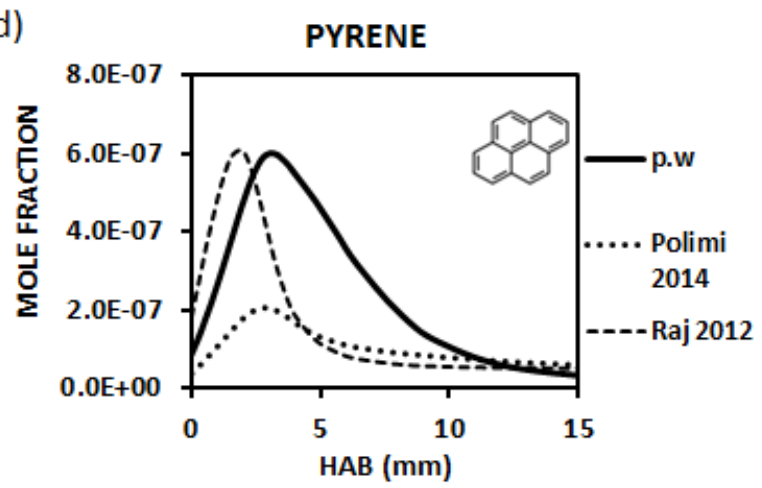

Fig.8. Predicted and experimental mole fractions of a): acetylene, b): benzene, c): naphthalene and d): pyrene in gasoline premixed flame $(\varphi=1.7 ; P=30$ Torr $)$. The symbols represent experimental data [85]; the continuous lines represent the modeling results from the present work; dashed lines: Raj et al. mechanism for gasoline surrogate [25] using (n-heptane/iso-octane/toluene: 13.7\% (\%vol)/42.9\%/43.4 from [87]) and dotted lines: Polimi mechanism[60].
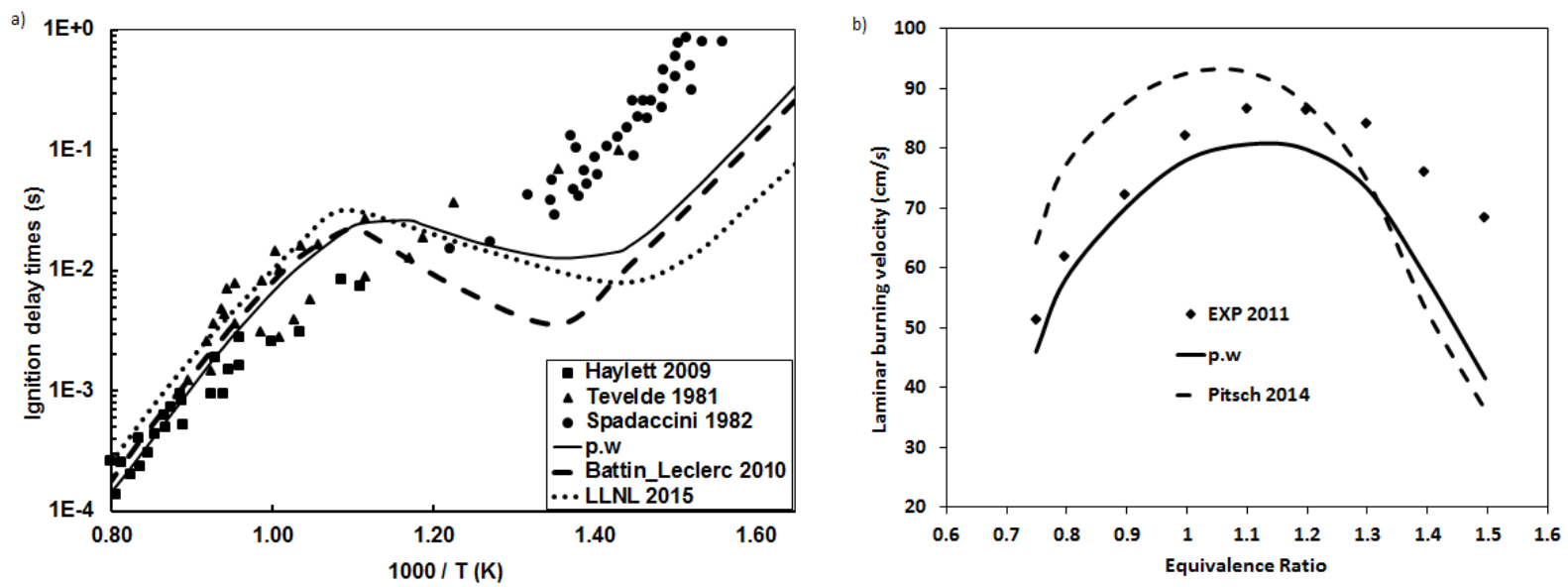

Fig.9. a): Diesel ignition delay times measurement in shock tube: diesel fuel $(0.7 \%) / \mathrm{O}_{2} / \mathrm{Ar} ; \varphi=0.5 ; \mathrm{P}=6$ atm ; T=600$1300 \mathrm{~K}$; The symbols represent experimental data from [90]; the continuous lines represent the modeling results from the present work; dashed lines: Battin_Leclerc et al. mechanism [92]; dotted lines: LLNL mechanism for diesel surrogate [93]. b): Laminar burning velocity of diesel fuel : $P=1 \mathrm{~atm} ; T_{u}=470 \mathrm{~K}$; The symbols represent experimental data from [91]; the continuous lines represent the modeling results from the present work; dashed lines: Pistsch et al. mechanism for diesel surrogate (n-dodecane) [98]. 

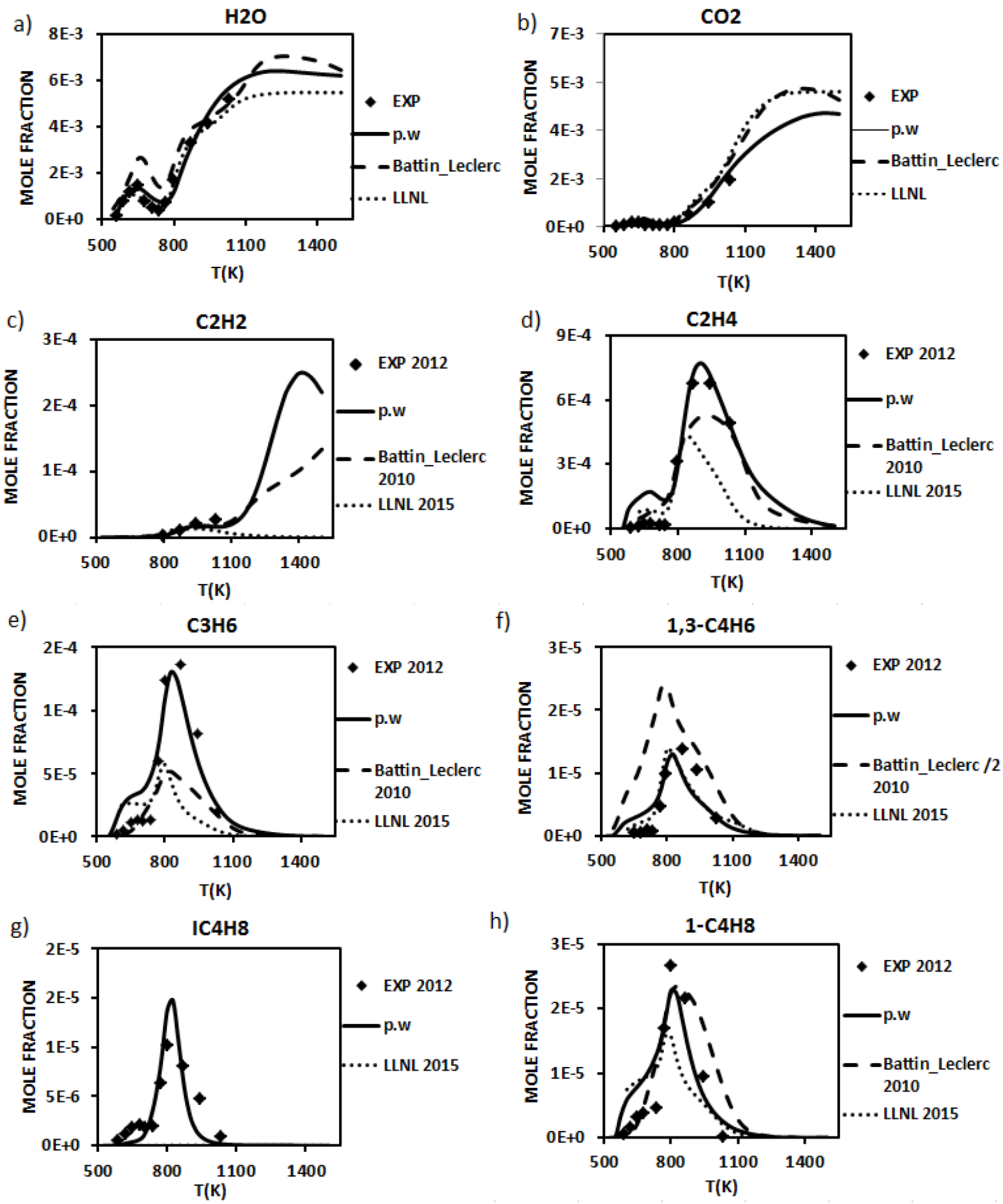

h)

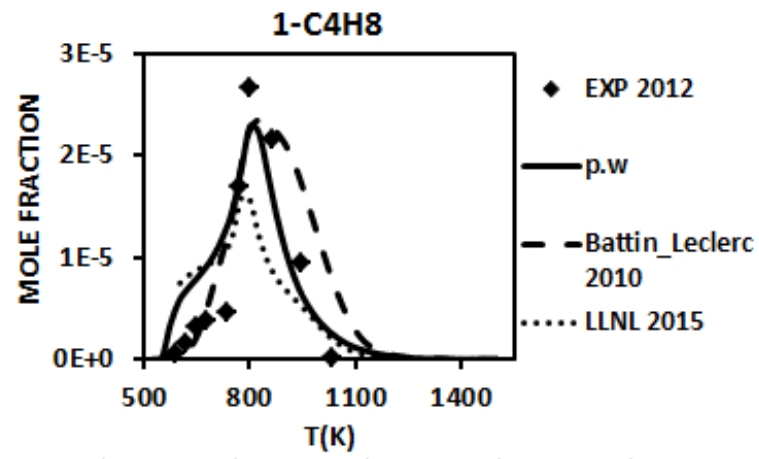

Fig.10. Diesel fuel $\left(\mathrm{C}_{15,64} \mathrm{H}_{29,34}\right)$ combustion in Jet stirred reactor: diesel fuel/ $\mathrm{O}_{2} / \mathrm{N}_{2}: 650 / 10,000 / 989,400$ in $\mathrm{ppmv} \varphi \varphi$ $=1.5 ; \mathrm{P}=10$ bar; $\tau=1 \mathrm{~s}$; predicted and experimental mole fractions of a) water, $\mathrm{b}$ ): carbon dioxide, c): acetylene, $\mathrm{d}$ ): ethylene, e): propene, f): 1,3-butadiene, $g$ ): iso-butene and $h$ ): 1-butene. The symbols represent experimental data [37]; the continuous lines represent the modeling results from the present work; dashed lines: Battin-Leclerc mechanism for diesel surrogate (n-decane/1-methylnaphthalene: $70(\% \mathrm{~mol}) / 30)$ [92]; dotted lines: Lawrence Livermore National Laboratory mechanism for diesel surrogate (n-dodecane/m-Xylene: 77 (\% vol)/23) (LLNL) [93].

The present mechanism was used to model premixed flames presented above, different fuels structures ranging from $\mathrm{C}_{1}$ to $\mathrm{C}_{10}$ species including liquid fuels, alkanes, alkenes, alkynes and aromatics. The overall agreement between predicted and experimental results remains fairly satisfactory. The 
performance of this reaction model with respect to practical fuels combustion modeling (ignition delay times and laminar flame speeds prediction) shows clearly encouraging results with the surrogate fuel proposed in this study. Satisfactory results are obtained in predicting ignition delay times, laminar flame speeds and species mole fraction profiles in jet stirred reactor configuration. The laboratory fuels such as ethylene and styrene combustion are also well represented in premixed laminar one dimensional flames configuration.. As can be seen in Fig.2 to Fig.10, the disagreement with experimental data is more important for gasoline premixed flame for which multiple sources of uncertainties may exist (notably surrogate model and kinetic model). Among the tested mechanisms, the present one gives the closest prediction of naphthalene concentration for gasoline premixed flame modeled in Fig.8. Further, for acetylene and benzene, a good agreement with experimental mole fraction profiles is obtained for all flames studied.

The current mechanism was subsequently used in atmospheric premixed flame configuration to study benzene and naphthalene formation pathways based on fuel structure. Since no aromatic species concentration profile is available in atmospheric premixed laminar flame configuration for diesel fuel, and due to due to the above-mentioned uncertainties on naphthalene prediction by the present model in gasoline premixed flame, we focused our analysis on two atmospheric rich premixed flames (ethylene and jet-A1). Local sensitivity analyses for these species were performed to highlight the role of reactions impacting benzene and naphthalene production. Results obtained for sensitivity analyses and rates of production analyses are presented in the following sections.

\subsection{Sensitivity analysis}

As the present mechanism was shown to perform fairly well over an extended range of operating conditions, it could be used with some confidence to perform local sensitivity analyses by computing the logarithmic derivatives of benzene and naphthalene concentrations with respect to the kinetic preexponential factors. Table 7 summarizes the operating conditions applied for the flames analyzed for benzene and naphthalene sensitivity analyses. The main aim of this analysis was to gain an overview not only on the nature of reactions which potentially impact benzene and naphthalene chemistry but also the nature of those conditioning benzene and naphthalene production. 


\begin{tabular}{|l|c|c|c|c|c|c|}
\hline Fuel & $\mathrm{X}_{\text {fuel }}$ & $\varphi$ & $\mathrm{P}(\mathrm{atm})$ & $\mathrm{T}_{\max }(\mathrm{K})$ at $\mathrm{mm}$ & $\mathrm{V}(\mathrm{cm} / \mathrm{s})$ & $\begin{array}{c}\text { Sensitivity analysis } \\
\text { point }(\mathrm{HAB})\end{array}$ \\
\hline Ethylene & 0.2100 & 3.06 & 1 & 1429 at 2.6 & 6.4 & From 0.5 to $12 \mathrm{~mm}$ \\
\hline Jet fuel & 0.0295 & 1.70 & 1 & 1779 at 2.5 & 11.7 & From 0.2 to $3 \mathrm{~mm}$ \\
\hline
\end{tabular}

Table 7 : Operating conditions considered, $\mathrm{X}$ : fuel mole fraction; $\varphi$ : Equivalence ratio; $\mathrm{V}$ : inlet cold gas velocity.

Fig.11 and Fig.12 show sensitivity analyses for benzene formation in ethylene and jet-A1 premixed flames.

a)

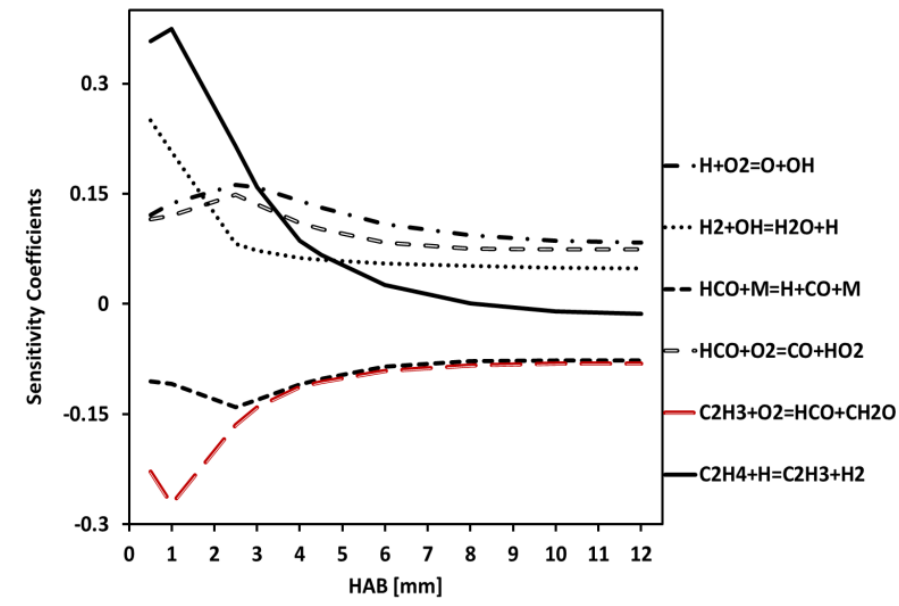

b)

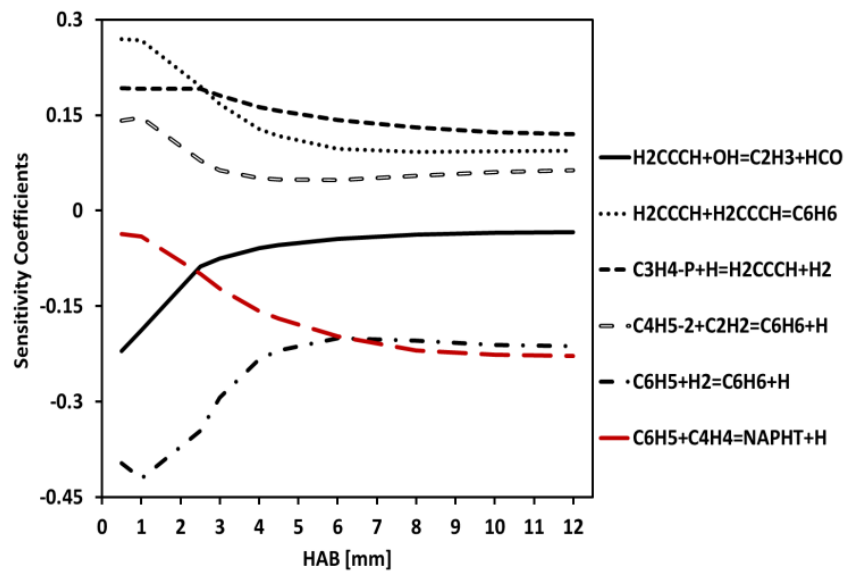

Fig.11. Normalized sensitivities for benzene formation in ethylene premixed flame.

a)

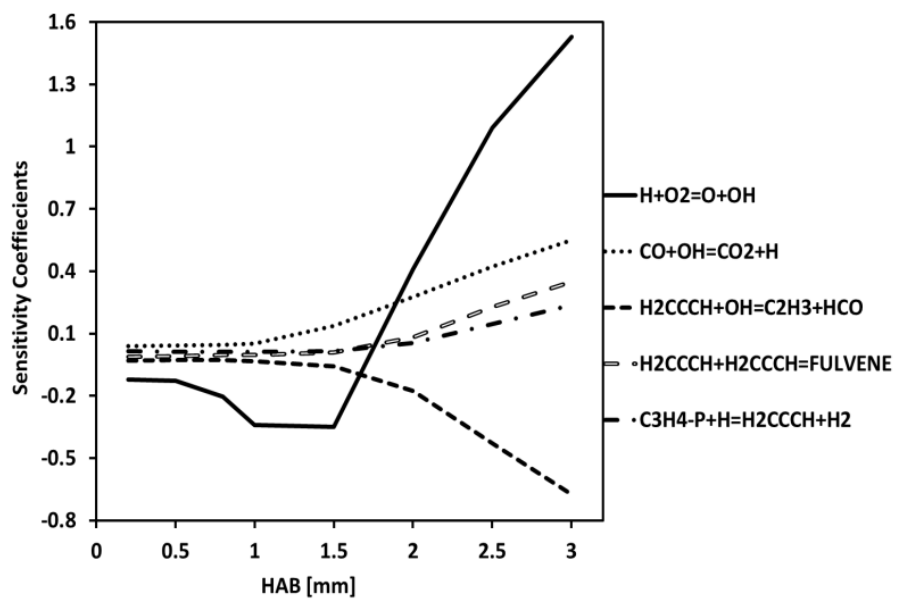

b)

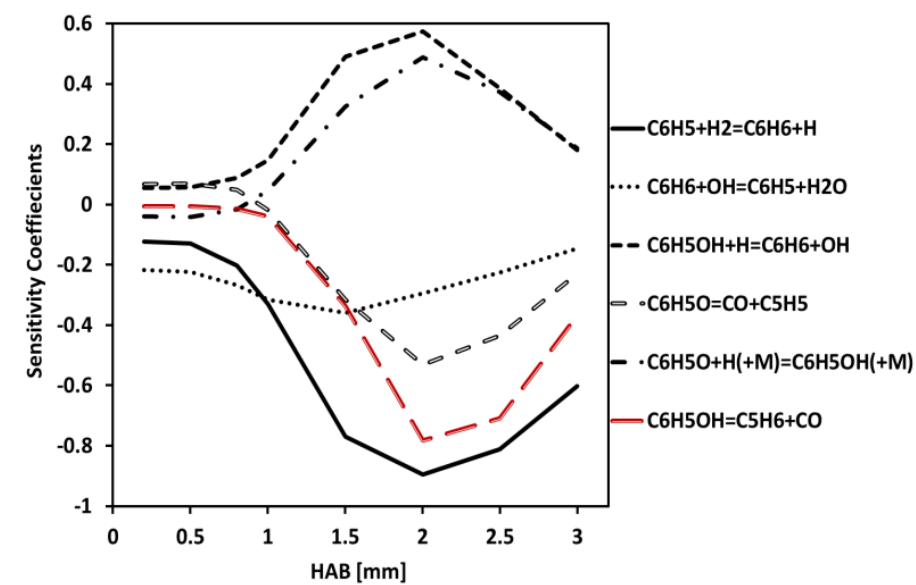

Fig.12. Normalized sensitivities for benzene formation in jet-A1 premixed flame.

As expected, the core $\mathrm{H}_{2}-\mathrm{O}_{2}$ reaction system plays an important role in benzene chemistry for both flames. For ethylene flame, reactions $\mathrm{H}+\mathrm{O}_{2}=\mathrm{O}+\mathrm{OH} ; \mathrm{H}_{2}+\mathrm{OH}=\mathrm{H}_{2} \mathrm{O}+\mathrm{H}$ and $\mathrm{HCO}+\mathrm{O}_{2}=\mathrm{CO}+\mathrm{HO}_{2}$ show 
positive sensitivities, indicating that reactions involving $\mathrm{OH}, \mathrm{H}$ and $\mathrm{HO}_{2}$ may contribute to benzene formation process through the formation of its precursors. Reaction $\mathrm{HCO}+\mathrm{M}=\mathrm{H}+\mathrm{CO}+\mathrm{M}$ produces $\mathrm{H}$ atom but a negative sensitivity is observed. In this case, formyl (HCO) decomposition may contribute to remove carbon from benzene production paths and $\mathrm{H}$ atom production through this step may favor $\mathrm{H}$-abstraction on benzene forming phenyl.

It is observed that reactions favoring the formation of vinyl radical, propargyl radical, fulvene, benzene and phenol show positive sensitivities, while those consuming vinyl radical, propargyl radical, phenyl radical, benzene and phenoxy radical show negative sensitivities. This is consistent with the fact that these species could be benzene precursors. One can note that the highest negative sensitivity for both flames is observed for reaction $\mathrm{C}_{6} \mathrm{H}_{5}+\mathrm{H}_{2}=\mathrm{C}_{6} \mathrm{H}_{6}+\mathrm{H}$. In addition, propargyl radicals (for ethylene flame) play a key role in benzene production in all flame zones, while reactions involving phenol (in the case of Jet-A1 flame) impact considerably benzene production from 1.0 to 3.0 mm (burnt gas zone).

Fig.13 and Fig.14 show sensitivity analyses for naphthalene formation in both flames. The core $\mathrm{H}_{2}-\mathrm{O}_{2}$ reaction system plays an important role as for benzene formation. In ethylene flame, reactions favoring naphthalene formation such as phenyl radical reaction with vinylacetylene; propargyl radicals recombination or production from propyne and vinyl radical production from ethylene exhibit positive sensitivities. Benzene is found to be a dominant precursor of naphthalene since reactions that favor its formation such as propargyl radicals recombination or its derived product such as phenyl radical show positive coefficients for naphthalene formation. Reactions consuming naphthalene such as naphthyl radical, indenyl radical and phenylacetylene formation or its precursors such as phenyl radical oxidation to yield phenyl peroxy radical $\left(\mathrm{C}_{6} \mathrm{H}_{5} \mathrm{OO}\right)$ show negative sensitivities. It is worth noting that the impacts of these reactions (except naphthyl radical formation reaction) on naphthalene formation tend to vanish at higher $\mathrm{HAB}(>3 \mathrm{~mm}$ ). That could be explained by the drop of sensitivity coefficients of reactions that favor naphthalene production, indicating there might be a competition between naphthalene reaction route and other reaction routes that produce indenyl radical such as $\mathrm{C}_{5} \mathrm{H}_{5}+\mathrm{C}_{4} \mathrm{H}_{2}$ [99] and phenyacelyne such as $\mathrm{C}_{6} \mathrm{H}_{5}+\mathrm{C}_{2} \mathrm{H}_{2}$ [100]. Phenyl peroxy $\left(\mathrm{C}_{6} \mathrm{H}_{5} \mathrm{OO}\right)$ may contribute to 
phenoxy radical $\left(\mathrm{C}_{6} \mathrm{H}_{5} \mathrm{O}\right)$ production, which is a precursor of cyclopentadienyl radicals which can then yield naphthalene by recombination $[13,101]$.

a)

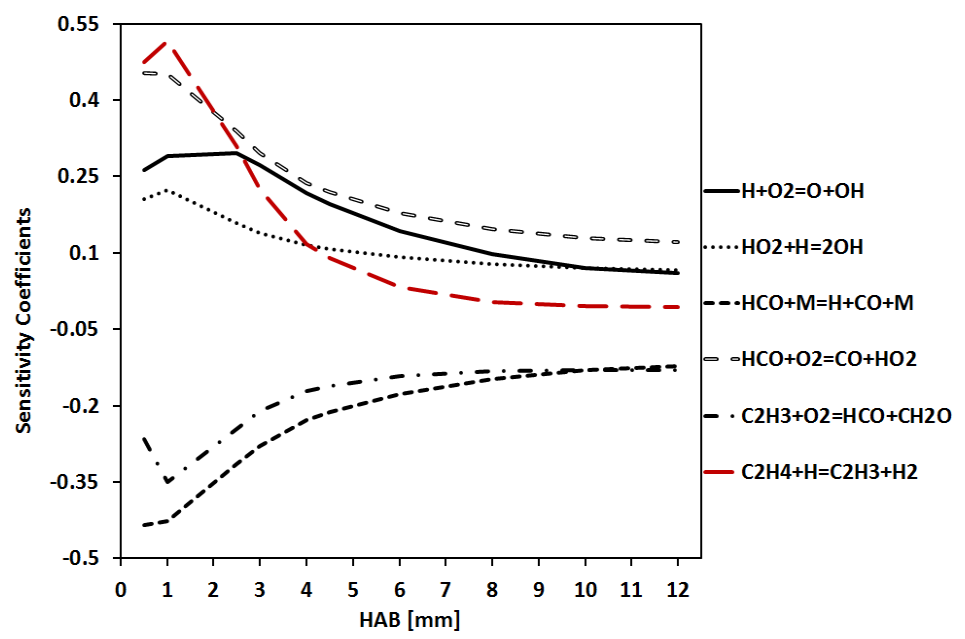

b)

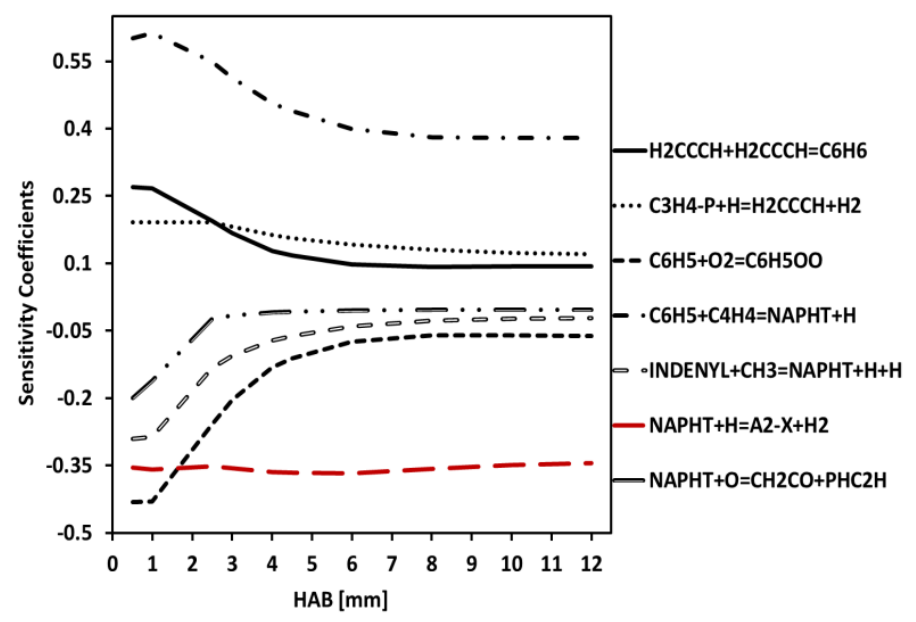

Fig.13. Normalized sensitivities for naphthalene formation in ethylene premixed flame.

a)

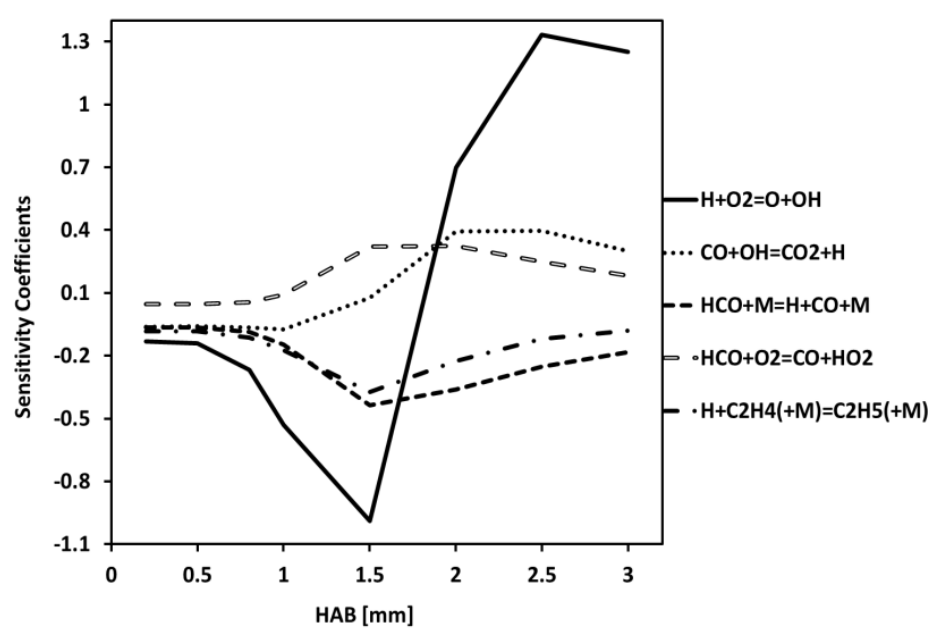

b)

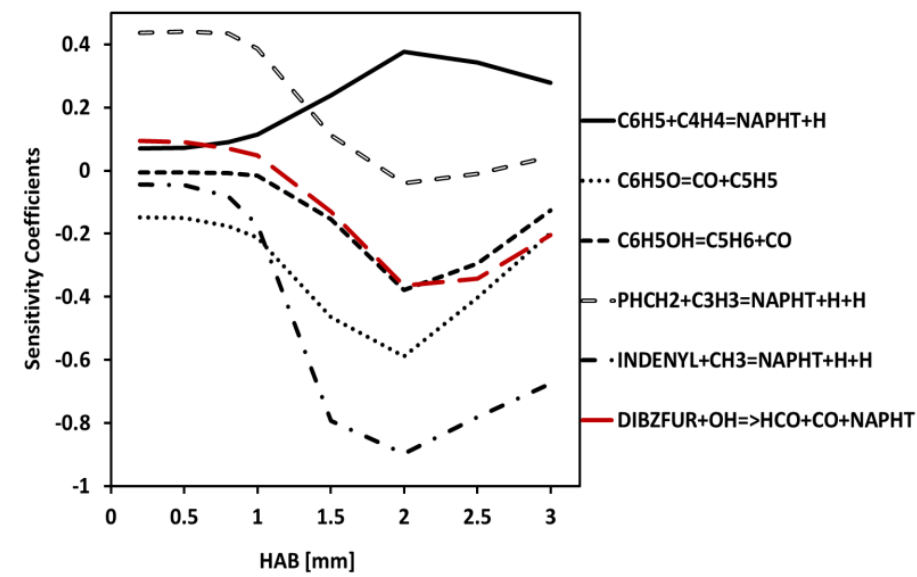

Fig.14. Normalized sensitivities for naphthalene formation in jet-A1 premixed flame.

In Jet-A1 flame, benzyl reaction with propargyl shows positive sensitivities from 0.2 to $1.8 \mathrm{~mm}$.

Beyond $1.8 \mathrm{~mm}$, this reaction does no longer impact naphthalene formation, implying that benzyl reaction route might be an important pathway from 0.2 to $1.8 \mathrm{~mm}$. Phenyl reaction with vinylacetylene shows positive sensitivities, indicating that this reaction may play an important role $[8,101]$ for naphthalene production from $1.0 \mathrm{~mm}$ to $3.0 \mathrm{~mm}$ (in burnt gas zone). Dibenzofuran oxidation reaction shows a contrasted behavior. The negative sensitivities observed for this reaction could be explained by the consumption of its precursor (i.e phenoxy), which also exhibits negative sensitivities by 
yielding cyclopentadienyl radical. In that case, cyclopentadienyl radicals do not seem to play an important role in naphthalene production since phenoxy radical consumption effect is more important than their production. Negative sensitivities observed for phenol decomposition reaction to yield cyclopentadiene $\left(\mathrm{C}_{5} \mathrm{H}_{6}\right)$ shows that this reaction may also impact naphthalene production.

\subsection{Rate of production analysis of benzene and naphthalene formation}

The present mechanism was subsequently used to analyze benzene and naphthalene production pathways. Major benzene and naphthalene formation pathways were analyzed for the two atmospheric rich premixed flames previously considered for sensitivity analysis, as depicted on Fig.15 and Fig.16. Although both flames were not studied under the same experimental conditions, their analysis can provide a global insight on PAHs formation from these two different fuel structures. Rates of production were obtained at the inflection point of benzene mole fraction profile which corresponds to a HAB of $2.5 \mathrm{~mm}$ (55.0\% of ethylene conversion) for ethylene flame and $0.4 \mathrm{~mm}(56.2 \%$ of jet-A1 fuel conversion) for jet-A1 flame. The absolute net reaction fluxes by numerical values are indicated next to the corresponding arrows. The boundary value corresponds to 1 nanomole per cubic centimeter per second and the relative contribution of reactions directly involved in benzene and naphthalene production is indicated in percent. The molecular structures of species discussed in this paper are presented in supplementary material. 


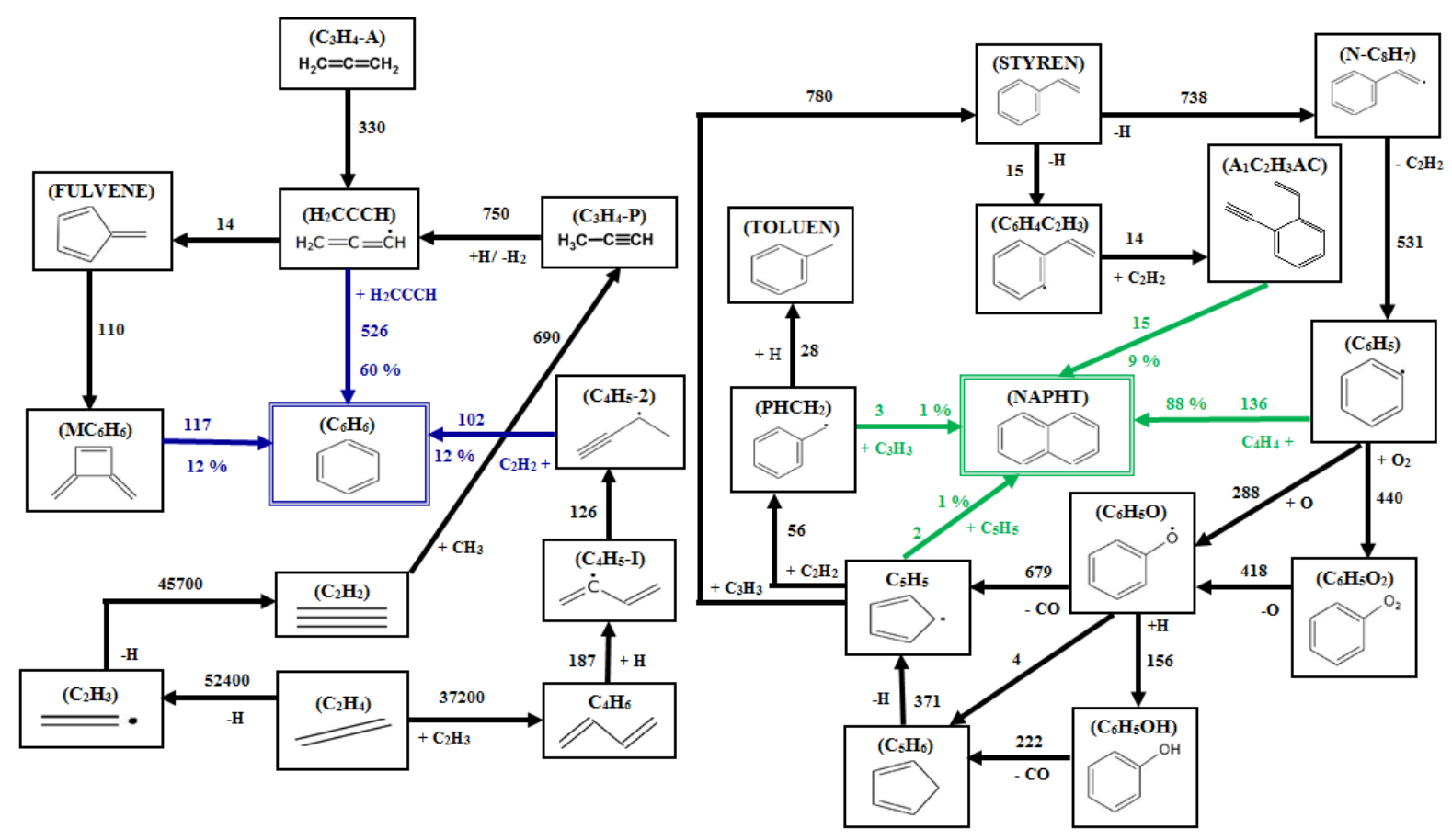

Fig.15. Major benzene and naphthalene formation pathways in ethylene flame: $H A B=2.5 \mathrm{~mm} ; \varphi=3.0 ; P=1 \mathrm{~atm}$; Reaction fluxes are expressed in nanomole per cubic centimeter per second.

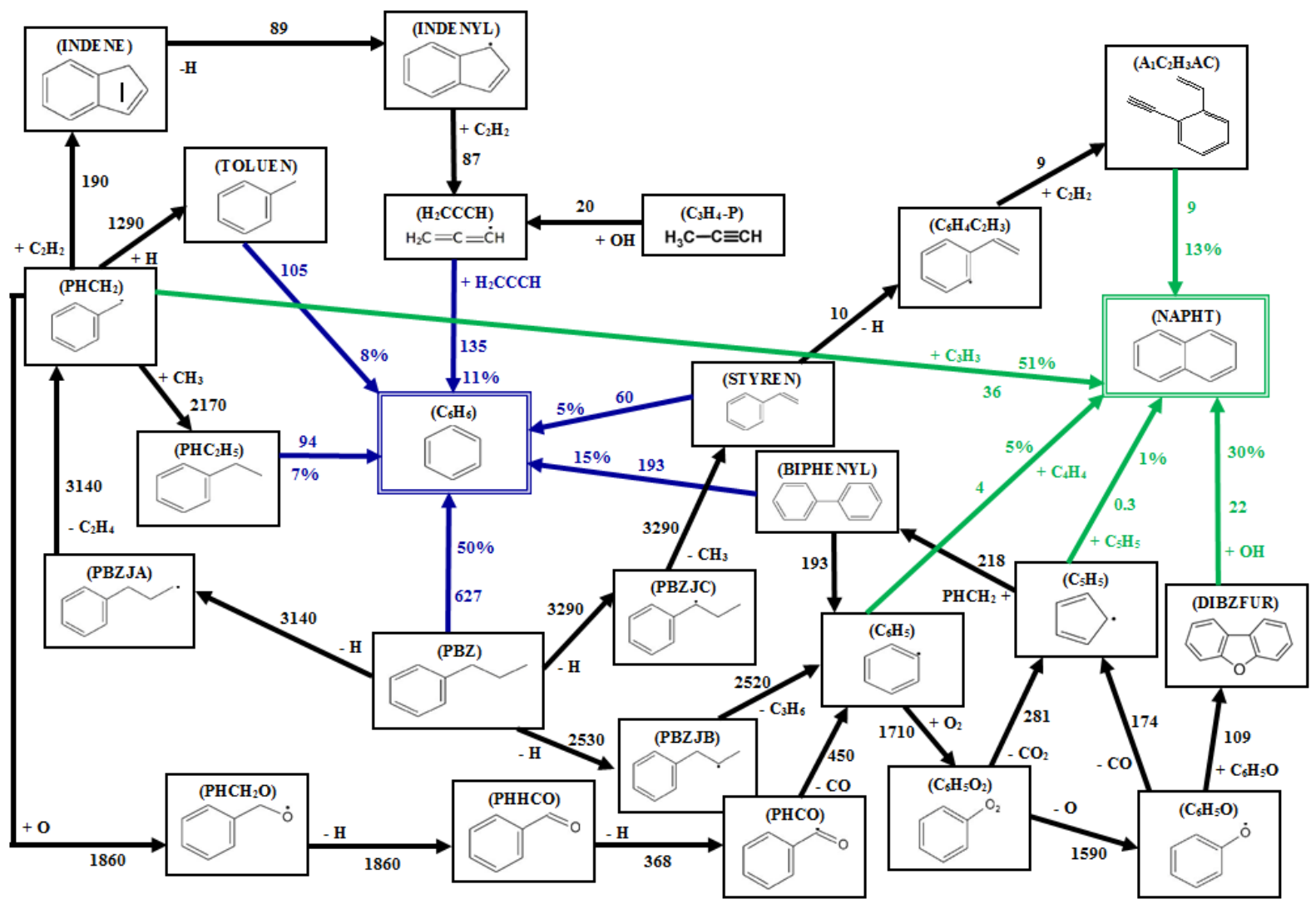

Fig.16. Major benzene and naphthalene formation pathways in jet-A1 fuel flame: $\mathrm{HAB}=0.4 \mathrm{~mm} ; \varphi=1.7 ; \mathrm{P}=1 \mathrm{~atm}$; Reaction fluxes are expressed in nanomole per cubic centimeter per second. 
As can be seen in Fig.15, benzene production is dominated by $\mathrm{C}_{3}$ species (propargyl radicals) recombination (60\%), followed by isomerization reaction of dimethylene cyclobutene $\left(\mathrm{MC}_{6} \mathrm{H}_{6}\right)(12 \%)$, and produced from fulvene, $\mathrm{C}_{4}$ species (2-butynyl $\mathrm{C}_{4} \mathrm{H}_{5}-2$ ) reaction with acetylene (12\%), $7 \%$ contribution from phenol decomposition reaction, and a minor contribution from styrene decomposition to yield vinyl radical (4\%), from toluene de-alkylation (3\%), and biphenyl decomposition to yield phenyl radical (2\%). Naphthalene is mainly produced from phenyl radical reaction with vinylacetylene (88\%), followed by vinyl phenyl acetylene $\left(\mathrm{A}_{1} \mathrm{C}_{2} \mathrm{H}_{3} \mathrm{AC}\right)$ rearrangement (9\%) and minor contributions of cyclopentadienyl radicals recombination (1\%) and benzyl reaction with propargyl (1\%).

Fig.16 shows the main reaction paths governing benzene formation in the rich atmospheric jet-A1 flame. Benzene formation is dominated by the consumption of n-propylbenzene (50\%) and biphenyl $(15 \%)$ by hydrogen atoms. $C_{3}$ species recombination reactions account for $11 \%, 8 \%$ from toluene dealkylation, $7 \%$ from ethylbenzene, 5\% from styrene and a minor contribution of $3 \%$ from benzaldehyde and phenol. Naphthalene formation is dominated by benzyl reaction with propargyl (51\%), followed by $31 \%$ contribution from dibenzofuran oxidation by $\mathrm{OH}, 13 \%$ contribution from vinyl phenyl acetylene $\left(\mathrm{A}_{1} \mathrm{C}_{2} \mathrm{H}_{3} \mathrm{AC}\right)$ rearrangement and a minor contribution of $5 \%$ from phenyl reaction with vinylacetylene. The self-recombination of cyclopentadienyl radicals reaction was found to be negligible in our conditions.

We also investigated the main reactions that produce benzene and naphthalene as a function of HAB, from 0.5 to $12.0 \mathrm{~mm}$ for ethylene flame and from 0.1 to $3.3 \mathrm{~mm}$ for jet-A1 flame. In Fig. 17 and Fig.18, we can notice that propargyl radicals recombination reaction, the fulvene derived product dimethylene cyclobutene $\left(\mathrm{MC}_{6} \mathrm{H}_{6}\right)$ and butyn-2-yl $\left(\mathrm{C}_{4} \mathrm{H}_{5}-2\right)$ reaction with acetylene appear as the main benzene production paths in atmospheric ethylene rich flame. Naphthalene production is dominated by phenyl reaction with vinylacetylene. Phenyl radical may probably exist in large concentration and vinylacetylene can be easily produced from acetylene reaction with vinyl radical reaction. For jet-A1 atmospheric rich flame, the nature of the intermediates involved in benzene production differs from those involved in ethylene flame case. From the current kinetic mechanism, benzene appears to be 
mainly formed from aromatic species such as toluene, biphenyl, ethylbenzene, n-propylbenzene and phenol (namely in burnt gas zone as shown in Fig.17). This is consistent with the fact that aromatics are well represented in jet-A1 and diesel fuels. Naphthalene production is dominated by benzyl reaction with propargyl. As many of the aromatic hydrocarbons in diesel and jet-A1 fuels contain alkylic side chains [102], they can readily produce benzyl radical by decomposition. The second important reaction identified for naphthalene production is that of dibenzofuran oxidation. Tritz et al. [22] proposed that dibenzofuran oxidation or pyrolysis could lead to naphthalene production proceeding through phenylacetylene intermediate. From the present kinetic study on jet-A1 surrogate oxidation, dibenzofuran decomposition process seems to emerge as one major naphthalene production pathway. The contribution of dibenzofuran oxidation to naphthalene production as a function of HAB in the investigated jet-A1 flame can be seen in Fig.18. It continuously produces naphthalene from $\mathrm{HAB}=0.1 \mathrm{~mm}$ (as a major pathway) to the burnt gas zone $(\mathrm{HAB}=3.3 \mathrm{~mm})$, while benzyl radical does no longer contribute to naphthalene production at $\mathrm{HAB}>1.5 \mathrm{~mm}$ since it is almost totally converted. While the present study only confirms the already established involvement of phenyl+vinylacetylene and benzyl+propargyl pathways in naphthalene production [103], the significant contribution of dibenzofuran was not proposed previously for jet A1 premixed flames.

It can also be observed in Fig.18 that the HACA mechanism contribution (represented here by vinyl phenyl acetylene $\left(\mathrm{A}_{1} \mathrm{C}_{2} \mathrm{H}_{3} \mathrm{AC}\right)$ path) for both flames is significant, while that of cyclopentadienyl radicals recombination reaction contributes barely to $5 \%$ of naphthalene production. Although Marinov and coworkers [13] concluded from their detailed modeling that cyclopentadienyl radicals route reaction could be the dominant naphthalene formation pathway in premixed aliphatic flames, McEnally and Pfefferle [104] deduced that benzyl addition to propargyl and HACA mechanism are viable routes from direct experimental evidence. The present results are consistent with this later assessment. However, dibenzofuran contribution to naphthalene formation had not been highlighted in the context of premixed flame literature prior to the present study. 

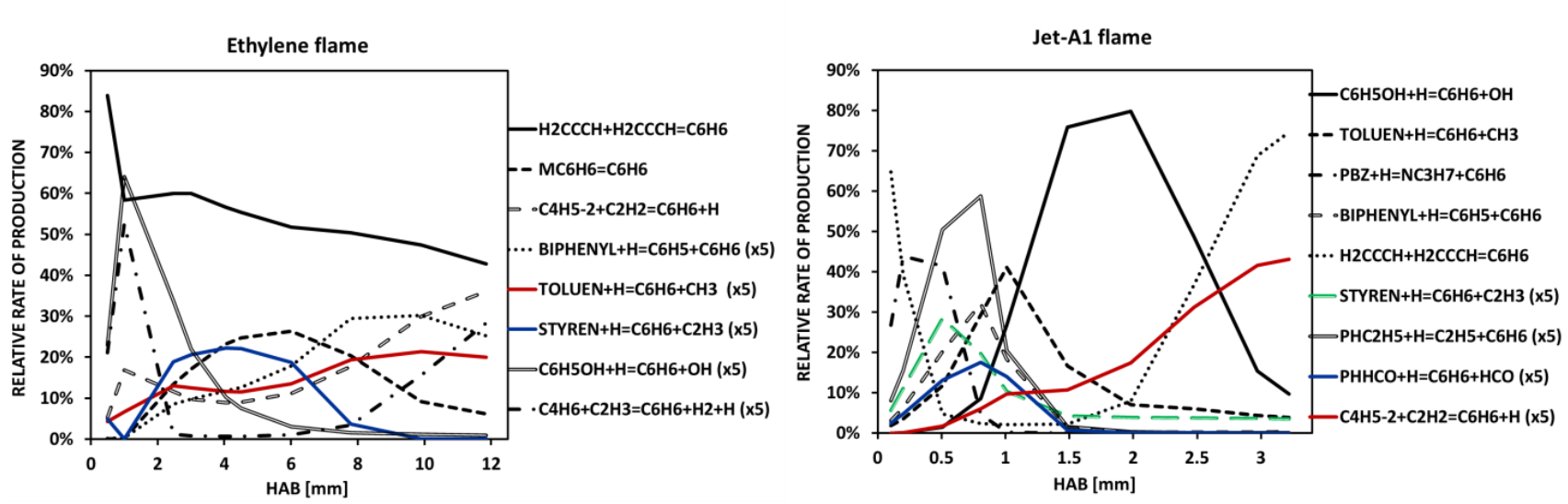

Fig.17. Relative rates of benzene production normalized by the total rate of production in ethylene and jet-A1 flames. The contributions of some reactions are multiplied by 5 as depicted in caption.
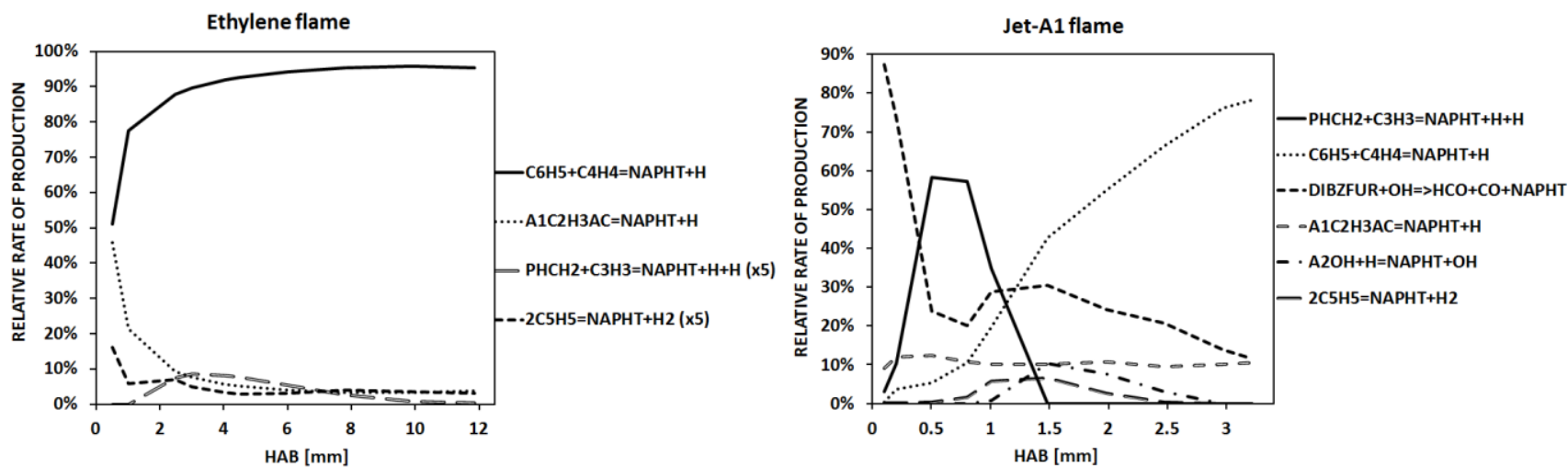

Fig.18. Relative rates of naphthalene production normalized by the total rate of production in ethylene and jet-A1 flames. The contributions of some reactions are multiplied by 5 as depicted in caption.

In summary, the reactions path analyses carried out on the formation of the first aromatic rings reinforce the oxygen involvement hypothesis in the activation of PAHs formation at high temperature. In this activation process, our calculations show that the phenoxy radical takes a central role. Unlike most of the literature mechanisms which consider that phenoxy is only a source of cyclopendienyl radicals, the present mechanism introduced a competition of the preceding step with that leading to a direct dibenzofuran formation. The presence of both reactions routes offers not only a better range of PAHs products as shown in Fig.15 and Fig.16, but also possible amphiphilic PAHs soot precursors due to the electronegative character of oxygen atoms.

\subsection{Thermal and chemical effects of fuel composition on naphthalene production paths}

To separate the chemical and thermal effects of fuel composition on PAH production paths [105], an additional fictive jet-A1 flame $(\Phi=1.7)$ with the same temperature profile and mass flow rate as 
ethylene flame at $\Phi=3.06$ was considered. It can be noticed that the thermal effect of fuel composition change leads to a slight shift in the location of naphthalene concentration peak (continuous lines versus dashed lines), while the effect of composition (continuous lines versus dotted lines) is dramatic, showing a monotonic trend (naphthalene being shifted further downstream). These calculations show that the chemical effect on naphthalene production is predominant over the thermal effect under the conditions investigated, which justifies the qualitative comparison of reaction path involved in the analyzed flames.

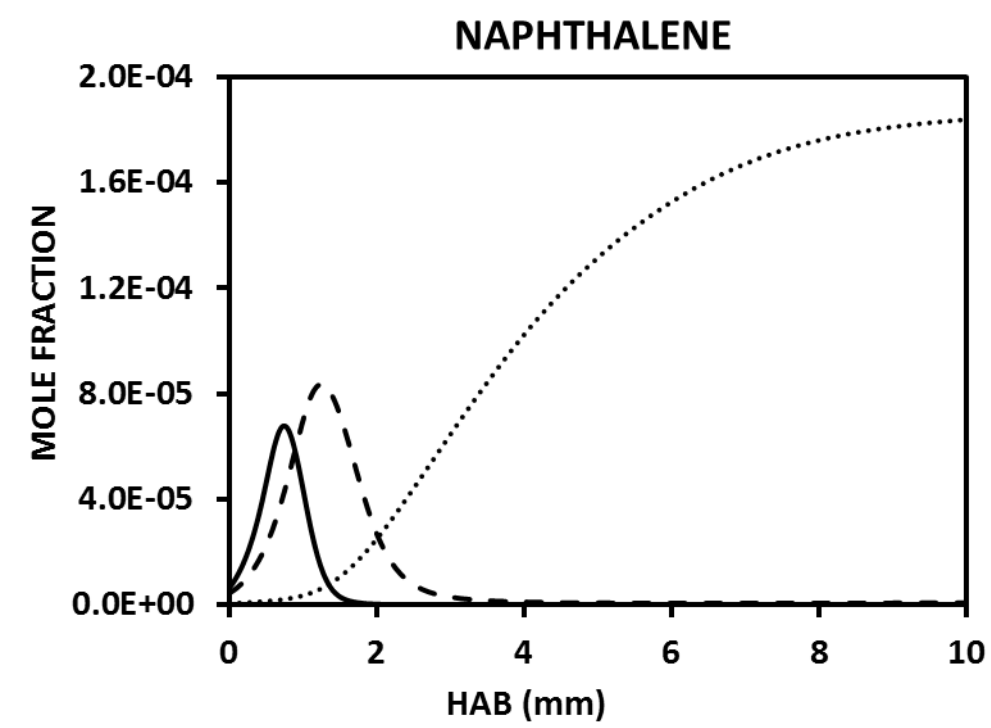

Fig.19. Naphthalene production profiles for a fictive flame of jet-A1 with the temperature profile of ethylene flame at $\Phi=3.06$. The continuous lines: jet-A1 flame with jet-A1 experimental temperature profile; the dash lines: a fictive jetA1 flame at $\Phi=1.7$ with the experimental temperature profile of ethylene flame at $\Phi=3.06$; the dotted lines: ethylene flame at $\Phi=3.06$ with experimental temperature profile of ethylene at $\Phi=3.06$. 


\section{Conclusions}

Benzene and naphthalene formation pathways for commercial liquid transportation fuels are seldom discussed in the literature and the present study aimed at determining the most significant ones in the light of the recent rate constant evaluations. A new detailed chemical kinetic mechanism was herein developed to describe accurately the combustion of liquid transportation fuels (gasoline, jet-A1 and diesel fuel) as well as laboratory fuels (single components) over an extended range of equivalence ratios, temperatures, pressures and dilution levels. Given the validations conditions shown in this paper, this mechanism is expected to work properly for the combustion of n-decane/iso-octane/n-propylbenzene mixtures for equivalence ratios ranging from 0.5 to 3 , temperature ranging from $600 \mathrm{~K}$ to $2500 \mathrm{~K}$ and pressures ranging from 0.01 atm to 10 atm.

Ternary surrogate mixtures of n-decane, iso-octane and n-propylbenzene were chosen to represent liquid transportation fuels, based on their Derived Cetane Number and Threshold Sooting Index. The impact of fuel formulation on benzene and naphthalene formation pathways was examined, focusing on two atmospheric premixed flames (ethylene and jet-A1). From the present modeling results, it turns out that jet-A1 and diesel fuels can be satisfactory represented by the proposed chemical surrogate, while gasoline may not be satisfactorily represented due to its high iso-octane concentration ( $75 \%$ vol. liq.), which is not representative of the actual gasoline composition in terms of PAH precursors, despite its ability to reproduce the sooting level through a relevant TSI value.

In line with previous studies from other groups, our study highlights the discrepancy between aromatics production pathways involved in laboratory flames (widely used in most academic soot formation studies) such as ethylene flame and those involved in actual liquid transportation fuel flames, calling for more representativity in the choice of reactive systems. Regarding naphthalene formation, common pathways were noticed for both flames. According to the present mechanism, phenyl+vinylacetylene and benzyl+propargyl reactions were shown to contribute massively to naphthalene production based on the retained rate constants for these reactions. In ethylene flame, 
phenyl+vinylacetylene reaction is the main path for naphthalene formation, while in jet-A1 flame phenyl+vinylacetylene and benzyl+propargyl are dominant naphthalene production pathways. The importance of reactions involved in benzene and naphthalene production was also seen to depend strongly on HAB. The HACA mechanism represented here by vinyl phenyl acetylene also plays a significant role in naphthalene production for both flames. It is worth noting that an additional pathway involving dibenzofuran oxidation to produce naphthalene was noticed in jet-A1 flame case. To the best of our knowledge, this reaction had not been evidenced previously as a significant naphthalene production pathway in the context of liquid fuel premixed flames. We herein claim that based on state-of-the art kinetic estimate for dibenzofuran production, this pathway can contribute significantly to naphthalene production over the whole combustion and post-combustion region. This pleads for further development and validation of oxygenated aromatics combustion mechanisms (such as dibenzofuran) as they might play a key role in PAH production for liquid transportation fuels flames. Further, more experimental data on the benzyl+propargyl interaction would be needed to validate the recent theoretical rate constants proposed. Other potential mechanisms such as the alternative HAVA (Hydrogen-AbstractionVinyl-Addition) mechanism would also deserve further studies. Finally, the present mechanism should be ultimately coupled to advanced soot models such as sectional models to account for the impact of soot nucleation and growth on PAH concentrations. This is the subject of on-going studies in our groups.

\section{Acknowledgments}

The authors are grateful for financial support from ANR (French National Research Agency), grant ANR-13-TDMO-0002 ASMAPE (Advanced Soot Model for Aeronautics and Piston Engines). 


\section{References}

[1] J.D. Herdman, J.H. Miller, Intermolecular potential calculations for polynuclear aromatic hydrocarbon clusters, J. phys. chem. A 112 (2008) 6249-6256.

[2] J. Kaiser, Showdown over clean air science, Science 277 (1997) 466-469.

[3] D.A. Kaden, R.A. Hites, W.G. Thilly, Mutagenicity of soot and associated polycyclic aromatic hydrocarbon to salmonella typhimurium, Cancer Res. 39 (1979) 4152-9.

[4] J.M. Wilson, M.T. Baeza-Romero, J.M. Jones, M. Pourkashanian, A. Williams, A.R. LeaLangton, A.B. Ross, K.D. Bartle, Biomass Pyrolysis Products and a Hydrocarbon Fuel, n Decane: An Aerosol Time Of Flight Mass Spectrometer (ATOFMS) Study, Energy Fuels 27 (2013) 1668-1678.

[5] H.R. Zhang, E.G. Eddings, A.F. Sarofim, C.K. Westbrook, Fuel dependence of benzene pathways, Proc. Combust. Inst. 32 (2009) 377-385.

[6] S. Sharma, M.R. Harper, W.H. Green, Modeling of 1,3-hexadiene, 2,4-hexadiene and 1,4hexadiene-doped methane flames: Flame modeling, benzene and styrene formation, Combust. Flame 157 (2010) 1331-1345.

[7] D. Boufflers, Etude expérimentale et Modélisation de la formation des suies et de leurs précurseurs en flamme de prémélange à différentes richesses (cas du n-C4H10), PhD Thesis, University of Lille 1, 2014.

[8] J. Appel, H. Bockhorn, M. Frenklach, Kinetic modeling of soot formation with detailed chemistry and physics: laminar premixed flames of C2 hydrocarbons, Combust. Flame 121 (2000) 122-136.

[9] N.A. Slavinskaya, U. Riedel, S.B. Dworkin, M.J. Thomson, Detailed numerical modeling of PAH formation and growth in non-premixed ethylene and ethane flames, Combust. Flame 159 (2012) 979-995.

[10] H. Wang, M. Yao, Z. Yue, M. Jia, R.D. Reitz, A reduced toluene reference fuel chemical kinetic mechanism for combustion and polycyclic-aromatic hydrocarbon predictions, Combust. Flame 162 (2015) 2390-2404.

[11] A. El Bakali., J.L Delfau, C. Vovelle, Experimental Study of 1 Atmosphere, Rich, Premixed n heptane and iso-octane Flames, Combust. Sci. Technol. 140 (1998) 69-91.

[12] N. Hansen, T. Kasper, B. Yang, T.A. Cool, W. Li, P.R. Westmoreland, P. Oßwald, K. KohseHöinghaus, Fuel-structure dependence of benzene formation processes in premixed flames fueled by C6H12 isomers, Proc. Combust. Inst. 33 (2011) 585-592.

[13] M.J. Castaldi, N.M. Marinov, C.F. Melius, J. Huang, S.M. Senkan, W.J. Pit, C.K. Westbrook, Experimental and modeling investigation of aromatic and polycyclic aromatic hydrocarbon formation in a premixed ethylene flame, Symp. (Int.) Combust. 26 (1996) 693-702.

[14] H. Wang, M. Frenklach, Calculations of Rate Coefficients for the Chemically Activated Reactions of Acetylene with Vinylic and Aromatic Radicals, J. Phys. Chem. 98 (1994) 1146511489.

[15] H. Anderson, C.S. McEnally, L.D. Pfefferle, Experimental study of naphthalene formation pathways in non-premixed methane flames doped with alkylbenzenes, Proc. Combust. Inst. 28 (2000) 2577-2583.

[16] D.S.N. Parker, R.I. Kaiser, B. Bandyopadhyay, O. Kostko, T.P. Troy, M. Ahmed, Unexpected Chemistry from the Reaction of Naphthyl and Acetylene at Combustion-Like Temperatures, Angew. Chem. 127 (2015) 5511-5514.

[17] M.B. Colket, D.J. Seery, Reaction mechanisms for toluene pyrolysis, Symp. (Int.) Combust. 25 (1994) 883-891.

[18] B. Shukla and M. Koshi, A highly efficient growth mechanism of polycyclic aromatic hydrocarbons, Phys. Chem. Chem. Phys. 12 (2010) 2427-2437. 
[19] Y. Li, L. Zhang, Z. Tian, T. Yuan, J. Wang, B. Yang, F. Qi, Experimental study of a fuel-rich premixed toluene flame at low pressure, Energy Fuels 23 (2009) 1473-1485.

[20] C.S. McEnally, L.D. Pfefferle, An Experimental Study in Non-Premixed Flames of Hydrocarbon Growth Processes that Involve Five-Membered Carbon Rings, Combust. Sci. Technol. 131 (1998) 323-344.

[21] E.B. Hemings, G. Bozzano, M. Dente, E. Ranzi, Detailed kinetics of the pyrolysis and oxidation of anisole, Chem. Eng. Trans., 24 (2011) 61-66.

[22] A. Tritz, I. Ziegler-Devin, C. Perrin, P.-M. Marquaire, Experimental study of the oxidation and pyrolysis of dibenzofuran at very low concentration, J. Env. Chem. Eng. 2 (2014) 143-153.

[23] J.M. Anderlohr, A. Piperel, A. Pires da Cruz, R. Bounaceur, F. Battin-Leclerc, P. Dagaut, X. Montagne, Influence of EGR compounds on the oxidation of an HCCI-diesel surrogate, Proc. Combust. Inst. 32 (2009) 2851-2859.

[24] H. Wang, M. Frenklach, A detailed kinetic modeling study of aromatics formation in laminar premixed acetylene and ethylene flames, Combust. Flame 110 (1997) 173-221.

[25] A. Raj, I.D.C. Prada, A.A. Amer, S.H. Chung, A reaction mechanism for gasoline surrogate fuels for large polycyclic aromatic hydrocarbons, Combust. Flame 159 (2012) 500-515.

[26] G. Blanquart, P. Pepiot-Desjardins, H. Pitsch, Chemical mechanism for high temperature combustion of engine relevant fuels with emphasis on soot precursors, Combust. Flame 156 (2009) 588-607.

[27] L. Cai, H. Pitsch, Optimized chemical mechanism for combustion of gasoline surrogate fuels, Combust. Flame 162 (2015) 1623-1637.

[28] C. Marchal, J.-L. Delfau, C. Vovelle, G. Moréac, C. Mouna1 m-Rousselle, F. Mauss, Modelling of aromatics and soot formation from large fuel molecules, Proc. Combust. Inst. 32 (2009) 753759.

[29] P. Dagaut, On the kinetics of hydrocarbons oxidation from natural gas to kerosene and diesel fuel, Phys. Chem. Chem. Phys. 4 (2002) 2079-2094.

[30] P.K. Senecal, E. Pomraning, K.J. Richards, T.E. Briggs, Multi-Dimensional Modeling of Direct-Injection Diesel Spray Liquid Length and Flame Lift-off Length using CFD and Parallel Detailed Chemistry, SAE Paper (2003-01-1043).

[31] D. Darcy, M. Mehl, J.M. Simmie, J. Würmel, W.K. Metcalfe, C.K. Westbrook, W.J. Pitz, H.J. Curran, An experimental and modeling study of the shock tube ignition of a mixture of $n$ heptane and n-propylbenzene as a surrogate for a large alkyl benzene, Proc. Combust. Inst. 34 (2013) 411-418.

[32] W. Schulz, Jet surrogate fuels formulation, ACS Petrol. Chem. Div. Preprints 37 (1991) 383392.

[33] S. Dooley, S.H. Won, M. Chaos, J. Heyne, Y. Ju, F.L. Dryer, K. Kumar, C.-J. Sung, H. Wang, M.A. Oehlschlaeger, R.J. Santoro, T.A. Litzinger, A jet fuel surrogate formulated by real fuel properties, Combust. Flame 157 (2010) 2333-2339.

[34] P. Dagaut, A. El Bakali, A. Ristori, The combustion of kerosene: Experimental results and kinetic modelling using 1- to 3-component surrogate model fuels, Fuel 85 (2006) 944-956.

[35] M. Mehl, W.J. Pitz, C.K. Westbrook, H.J. Curran, Kinetic modeling of gasoline surrogate components and mixtures under engine conditions, Proc. Combust. Inst. 33 (2011) 193-200.

[36] G. Kukkadapu, K. Kumar, C.-J. Sung, M. Mehl, W.J. Pitz, Autoignition of gasoline surrogates at low temperature combustion conditions, Combust. Flame 162 (2015) 2272-2285.

[37] H. Ramirez Lancheros, Etude expérimentale et modélisation cinétique de l'oxydation, l'autoinflammation et la combustion de carburants Diesel et bio-Diesel, $\mathrm{PhD}$ Thesis, University of Orleans, 2012. 
[38] Y. Yang, A.L. Boehman, R.J. Santoro, A study of jet fuel sooting tendency using the threshold sooting index (TSI) model, Combust. Flame 149 (2007) 191-205.

[39] R. Lemaire, E. Therssen, P. Desgroux, Effect of ethanol addition in gasoline and gasolinesurrogate on soot formation in turbulent spray flames, Fuel 89 (2010) 3952-3959.

[40] S. Dooley, S.H. Won, J. Heyne, T.I. Farouk, Y. Ju, F.L. Dryer, K. Kumar, X. Hui, C.-J. Sung, H. Wang, M.A. Oehlschlaeger, V. Iyer, S. Iyer, T.A. Litzinger, R.J. Santoro, T. Malewicki, K. Brezinsky, The experimental evaluation of a methodology for surrogate fuel formulation to emulate gas phase combustion kinetic phenomena, Combust. Flame 159 (2012) 1444-1466.

[41] J.C. Guibet, fuels and engines, Pub. IFP éditions Technip, Rueil-Malmaison, France, 1999.

[42] N. Grumman, Diesel Fuel Oils 2003, Report NGMS-232 PPS, 2004.

[43] W.J. Pitz, N.P. Cernansky, F.L. Dryer, F.N. Egolfopoulos, J.T. Farell, D.G. Friend, H. Pitsch, Development of an Experimental Database and Chemical Kinetic Models for Surrogate Gasoline Fuels, SAE Paper 2007-01-0175, 2007, USA.

[44] N.E. Sánchez, A. Callejas, Á. Millera, R. Bilbao, M.U. Alzueta, Influence of the Oxygen Presence on Polycyclic Aromatic Hydrocarbon (PAH) Formation from Acetylene Pyrolysis under Sooting Conditions, Energy Fuels 27 (2013) 7081-7088.

[45] W.K. Metcalfe, S.M. Burke, S.S. Ahmed, H.J. Curran, A Hierarchical and Comparative Kinetic Modeling Study of C 1 - C 2 Hydrocarbon and Oxygenated Fuels, Int. J. Chem. Kinet. 45 (2013) 638-675.

[46] N. Hansen, J.A. Miller, P.R. Westmoreland, T. Kasper, K. Kohse-Höinghaus, J. Wang, T.A. Cool, Isomer-specific combustion chemistry in allene and propyne flames, Combust. Flame 156 (2009) 2153-2164.

[47] M.B. Colket, The pyrolysis of acetylene and vinylacetylene in a single-pulse shock tube, Symp. (Int.) Combust. 21 (1988) 851-864.

[48] Z. Wang, Y. Li, F. Zhang, L. Zhang, W. Yuan, Y. Wang, F. Qi, An experimental and kinetic modeling investigation on a rich premixed n-propylbenzene flame at low pressure, Proc. Combust. Inst. 34 (2013) 1785-1793.

[49] M. Zeng, W. Yuan, Y. Wang, W. Zhou, L. Zhang, F. Qi, Y. Li, Experimental and kinetic modeling study of pyrolysis and oxidation of n-decane, Combust. Flame 161 (2014) 1701-1715.

[50] E. Ranzi, C. Cavallotti, A. Cuoci, A. Frassoldati, M. Pelucchi, T. Faravelli, New reaction classes in the kinetic modeling of low temperature oxidation of n-alkanes, Combust. Flame 162 (2015) $1679-1691$.

[51] Y. Wenhao, Y. Li, P. Dagaut, J. Yang, F. Qi, Investigation on the pyrolysis and oxidation of toluene over a wide range conditions. I. Flow reactor pyrolysis and jet stirred reactor oxidation, Combust. Flame 162 (2015) 3-21.

[52] N.A. Slavinskaya, P. Frank, A modelling study of aromatic soot precursors formation in laminar methane and ethene flames, Combust. Flame 156 (2009) 1705-1722.

[53] A. Matsugi, A. Miyoshi, Modeling of two- and three-ring aromatics formation in the pyrolysis of toluene, Proc. Combust. Inst. 34 (2013) 269-277.

[54] K. Norinaga, O. Deutschmann, Detailed kinetic modeling of gas-phase reactions in the chemical vapor deposition of carbon from light hydrocarbons, Ind. Eng. Chem. Res. 46 (2007) 35473557.

[55] A. Kousoku, K. Norinaga and K. Miura, Extended Detailed Chemical Kinetic Model for Benzene Pyrolysis with New Reaction Pathways Including Oligomer Formation, Ind. Eng. Chem. Res. 53 (2014) 7956-7964.

[56] M.R. Djokic, An experimental and kinetic modeling study of cyclopentadiene pyrolysis: First growth of polycyclic aromatic hydrocarbons, Combust. Flame 161 (2014) 2739-2751. 
[57] N.E. Sánchez, A. Callejas, Á. Millera, R. Bilbao, M.U. Alzueta, Influence of the Oxygen Presence on Polycyclic Aromatic Hydrocarbon (PAH) Formation from Acetylene Pyrolysis under Sooting Conditions, Energy Fuels 27 (2013) 7081-7088.

[58] W. Yuan, Investigation on the pyrolysis and oxidation of toluene over a wide range conditions. I. Flow reactor pyrolysis and jet stirred reactor oxidation, Combust. Flame 162 (2015) 3-21.

[59] A. Kousoku, K. Norinaga and K. Miura, Extended Detailed Chemical Kinetic Model for Benzene Pyrolysis with New Reaction Pathways Including Oligomer Formation, Ind. Eng. Chem. Res. 53 (2014) 7956-7964.

[60] E. Ranzi, A. Frassoldati, A. Stagni, M. Pelucchi, A. Cuoci, T. Faravelli, Reduced Kinetic Schemes of Complex Reaction Systems: Fossil and Biomass-Derived Transportation Fuels, Int. J. Chem. Kinet., 46 (2014) 512-542.

[61] N. Sebbar, H. Bockhorn, J.W. Bozzelli, Thermochemical Similarities Among Three Reaction Systems: Vinyl + O2 - Phenyl + O2 - Dibenzofuranyl + O2, Combust. Sci. Technol. 180 (2008) 959-974.

[62] B. Yang, Y. Li, L. Wei, C. Huang, J. Wang, Z. Tian, R. Yang, L. Sheng, Y. Zhang, F. Qi, An experimental study of the premixed benzene/oxygen/argon flame with tunable synchrotron photoionization, Proc. Combust. Inst., 31 (2007) 555-563.

[63] R. Asatryan, A. Davtyan, L. Khachatryan, B. Dellinger, Molecular modeling studies of the reactions of phenoxy radical dimers: pathways to dibenzofurans, J. Phys. Chem. A 109 (2005) 11198-11205.

[64] H.H. Grotheer, R. Louw, The reaction of phenoxy radicals with mono-chlorobenzene and its meaning for gas-phase dioxin formation in incineration, Proc. Combust. Inst., 26 (1996) 24052411.

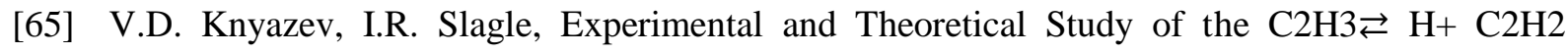
Reaction. Tunneling and the Shape of Falloff Curves, J. Phys. Chem. 100 (1996) 16899-16911.

[66] A.M. Mebel, M.C. Lin, T. Yu, K. Morokuma, Theoretical study of potential energy surface and thermal rate constants for the C6H5+ H2 and C6H6+ H reactions, J. Phys. Chem. A 101 (1997) 3189-3196.

[67] S.J. Klippenstein, L.B. Harding, Y. Georgievskii, On the formation and decomposition of C7H8, Proc. Combust. Inst. 31 (2007) 221-229.

[68] R. Bounaceur, I. Da Costa, R. Fournet, F. Billaud, F. Battin-Leclerc, Experimental and modeling study of the oxidation of toluene, Int. J. Chem. Kinet. 37 (2005) 25-49.

[69] G. da Silva, J.W. Bozzelli, Kinetic modeling of the benzyl+HO2 reaction, Proc. Combust. Inst. 32 (2009) 287-294.

[70] D.L. Baulch, C.T. Bowman, C.J. Cobos, R.A. Cox, T. Just, J.A. Kerr, M.J. Pilling, D. Stocker, Evaluated Kinetic Data for Combustion Modeling: Supplement II, J. Phys. Chem. Ref. Data 34 (2005) 757.

[71] J.A. Miller, J.P. Senosiain, S.J. Klippenstein, Y. Georgievskii, Reactions over Multiple, Interconnected Potential Wells: Unimolecular and Bimolecular Reactions on a C3H5 Potential, J. Phys. Chem. A 112 (2008) 9429-9438.

[72] Y. Georgievskii, S.J. Klippenstein, J.A. Miller, Association rate constants for reactions between resonance-stabilized radicals: $\mathrm{C} 3 \mathrm{H} 3+\mathrm{C} 3 \mathrm{H} 3, \mathrm{C} 3 \mathrm{H} 3+\mathrm{C} 3 \mathrm{H} 5$, and $\mathrm{C} 3 \mathrm{H} 5+\mathrm{C} 3 \mathrm{H} 5$, Phys. Chem. Chem. Phys. 9 (2007) 4259-4268.

[73] J.A. Miller, S.J. Klippenstein, The recombination of propargyl radicals and other reactions on a C6H6 potential, J. Phys. Chem. A 107 (2003) 7783-7799.

[74] J. Appel, H. Bockhorn, M. Frenklach, Kinetic modeling of soot formation with detailed chemistry and physics: laminar premixed flames of C2 hydrocarbons, Combust. Flame 121 (2000) 122-136. 
[75] A. Laskin, Thermal decomposition of indene. Experimental results and kinetic modeling, Proc. Combust. Inst. 27 (1998) 313-320.

[76] K. Brezinski, T. A. Litzinger, I. Glassman, The high temperature oxidation of the methyl side chain of toluene, Int. J. Chem. Kinet. 16 (1984) 1053-1074.

[77] N.W. Moriarty, M. Frenklach, AB initio study of naphthalene formation by addition of vinylacetylene to phenyl, Proc. Combust. Inst. 28 (2000) 2563-2568.

[78] A. Matsugi, A. Miyoshi, Computational study on the recombination reaction between benzyl and propargyl radicals, Int. J. Chem. Kinet. 44 (2012) 206-218.

[79] A. El Bakali, X. Mercier, M. Wartel, F. Acevedo, I. Burns, L. Gasnot, J.-F. Pauwels, P. Desgroux, Modeling of PAHs in low pressure sooting premixed methane flame, Energy 43 (2012) 73-84.

[80] Reaction Design, Reaction Workbench 15131, Reaction Design: San Diego, USA, 2013.

[81] J. Yang, L. Zhao, W. Yuan, F. Qi, Y. Li, Experimental and kinetic modeling investigation on laminar premixed benzene flames with various equivalence ratios, Proc. Combust. Inst. 35 (2015) 855-862.

[82] C. Douté, J.L Delfau, R. Akrich, C. Vovelle, Chemical Structure of Atmospheric Pressure Premixed n -Decane and Kerosene Flames, Combust. Sci. Technol. 106 (1995) 327-344.

[83] W. Yuan, Y. Li, P. Dagaut, J. Yang, F. Qi, Experimental and kinetic modeling study of styrene combustion, Combust. Flame 162 (2015) 1868-1883.

[84] Y. Li, J. Cai, L. Zhang, J. Yang, Z. Wang, F. Qi, Experimental and modeling investigation on premixed ethylbenzene flames at low pressure, Proc. Combust. Inst. 33 (2011) 617-624.

[85] Y. Li, C. Huang, L. Wei, B. Yang, J. Wang, Z. Tian, T. Zhang, L. Sheng, F. Qi, An Experimental Study of Rich Premixed Gasoline/O 2 /Ar Flame with Tunable Synchrotron Vacuum Ultraviolet Photoionization, Energy Fuels 21 (2007) 1931-1941.

[86] G. Kukkadapu, K. Kumar, C.-J. Sung, M. Mehl, W.J. Pitz, Autoignition of gasoline and its surrogates in a rapid compression machine, Proc. Combust. Inst. 34 (2013) 345-352.

[87] P. Dirrenberger, P.A. Glaude, R. Bounaceur, H. Le Gall, da Cruz, A. Pires, A.A. Konnov, F. Battin-Leclerc, Laminar burning velocity of gasolines with addition of ethanol, Fuel 115 (2014) 162-169.

[88] S.S. Vasu, D.F. Davidson, R.K. Hanson, Jet fuel ignition delay times: Shock tube experiments over wide conditions and surrogate model predictions, Combust. Flame 152 (2008) 125-143.

[89] X. Hui, C.-J. Sung, Laminar flame speeds of transportation-relevant hydrocarbons and jet fuels at elevated temperatures and pressures, Fuel 109 (2013) 191-200.

[90] D.R. Haylett, P.P. Lappas, D.F. Davidson, R.K. Hanson, Application of an aerosol shock tube to the measurement of diesel ignition delay times, Proc. Combust. Inst. 32 (2009) 477-484.

[91] C.T. Chong, S. Hochgreb, Measurements of laminar flame speeds of liquid fuels: Jet-A1, diesel, palm methyl esters and blends using particle imaging velocimetry (PIV), Proc. Combust. Inst. 33 (2011) 979-986.

[92] H. Wang, S.J. Warner, M.A. Oehlschlaeger, R. Bounaceur, J. Biet, P.-A. Glaude, F. BattinLeclerc, An experimental and kinetic modeling study of the autoignition of $\alpha$ methylnaphthalene/air and $\alpha$-methylnaphthalene/n-decane/air mixtures at elevated pressures, Combust. Flame 157 (2010) 1976-1988.

[93] Y. Pei, M. Mehl, W. Liu, T. Lu, W.J. Pitz, S. Som, A Multicomponent Blend as a Diesel Fuel Surrogate for Compression Ignition Engine Applications, J. Eng. Gas Turbines Power 137 (2015) 111502.

[94] J. Yang, L. Zhao, W. Yuan, F. Qi, Y. Li, Experimental and kinetic modeling investigation on laminar premixed benzene flames with various equivalence ratios, Proc. Combust. Inst. 35 (2015) 855-862. 
[95] Y. Li, J. Cai, L. Zhang, J. Yang, Z. Wang, F. Qi, Experimental and modeling investigation on premixed ethylbenzene flames at low pressure, Proc. Combust. Inst. 33 (2011) 617-624.

[96] M. Mehl, W.J. Pitz, C.K. Westbrook, H.J. Curran, Kinetic modeling of gasoline surrogate components and mixtures under engine conditions, Proc. Combust. Inst. 33 (2011) 193-200.

[97] C. Pera, V. Knop, Methodology to define gasoline surrogates dedicated to auto-ignition in engines, Fuel 96 (2012) 59-69.

[98] K. Narayanaswamy, P. Pepiot, H. Pitsch, A chemical mechanism for low to high temperature oxidation of n-dodecane as a component of transportation fuel surrogates, Combust. Flame 161 (2014) 866-884.

[99] V.D. Knjazev, and I.R. Slagle, Kinetics of the reaction between propargyl radical and acetylene, J. Phys. Chem. A 106 (2002) 5613-5617.

[100] S. Granata, T. Faravelli, E. Ranzi, N. Olten, S. Senkan, Kinetic modeling of counterflow diffusion flames of butadiene, Combust. Flame 131 (2002) 273-284.

[101] B. Shukla and M. Koshi, Comparative study on the growth mechanisms of PAHs, Combust. Flame 158 (2011) 369-375.

[102] R.P. Lindstedt, Modeling of the chemical complexities of flames, Proc. Combust. Inst. 27 (1998) 269-285.

[103] P. Lindstedt, L. Maurice, M. Meyer, Thermodynamic and kinetic issues in the formation and oxidation of aromatic species, Faraday Disc. 119 (2001) 409-432.

[104] C.S. McEnally, L.D. Pfefferle, The use of carbon-13-labeled fuel dopants for identifying naphthalene formation pathways in non-premixed flames, Proc. Combust. Inst. 28 (2000) 25692576.

[105] S. Bougrine, S. Richard, A. Nicolle, D. Veynante, Numerical study of laminar flame properties of diluted methane-hydrogen-air flames at high pressure and temperature using detailed chemistry, Int. J. Hydrogen Energy, 36 (2011) 12035-12047. 